\title{
VEGF-dependent and PDGF- dependent dynamic neurovascular reconstruction in the neurohypophysis of adult mice
}

\author{
Eriko Furube', Tetsuya Mannari', Shoko Morita ${ }^{1,2}$, Kazunori Nishikawa', \\ Ayaka Yoshida', Masanobu Itoh' ${ }^{1}$ and Seiji Miyata'
}

${ }^{1}$ Department of Applied Biology, Kyoto Institute of Technology, Matsugasaki, Sakyo-ku, Kyoto 606-8585, Japan ${ }^{2}$ Department of Anatomy and Neuroscience, Faculty of Medicine, Nara Medical University, Shijo-cho, Kashihara, Nara 634-8521, Japan
Correspondence should be addressed to S Miyata

Email smiyata@kit.ac.jp

\begin{abstract}
Hypothalamo-neurohypophysial system (HNS) releases arginine vasopressin (AVP) and oxytocin (OXT) from axonal terminals of the neurohypophysis (NH) into blood circulation for controlling body fluid homeostasis and lactation. Chronic osmotic and suckling stimulations have been shown to cause neurovascular and neuroglial reconstruction in the $\mathrm{NH}$ of adult mammals and no study has been reported for vascular dynamics. The aim of this study was to elucidate the occurrence of continuous angiogenesis and growth factor-dependent neurovascular reconstruction in the $\mathrm{NH}$ of adult mice. Active proliferation of endothelial cells and oligodendrocyte progenitor cells (OPCs) was observed using the immunohistochemistry of bromodeoxyuridine and Ki-67. Vascular endothelial growth factor A (VEGFA) and VEGF receptor 2 (VEGFR2 (KDR)) were highly expressed at pituicytes and endothelial cells respectively. Moreover, prominent expression of platelet-derived growth factor $B$ (PDGFB) and PDGF receptor beta was observed at OXT-containing axonal terminals and pericytes respectively. Administration of the selective tyrosine kinase inhibitor AZD2171 for VEGFRs and STI571 for PDGFRs significantly decreased proliferation of endothelial cells and OPCs. Moreover, AZD2171 treatment decreased vascular density by facilitating apoptosis of endothelial cells and the withdrawal of its treatment led to remarkable rebound proliferation of endothelial cells, so that vascular density rapidly returned to normal levels. AZD2171 decreased the density of both AVP- and OXT-containing axonal terminals, whereas STI571 selectively decreased the density of AVP-containing ones. Thus, this study demonstrates that the signaling pathways of VEGF and PDGF are crucial mediators for determining proliferation of endothelial cells and OPCs and the density of AVP- and OXT-containing axonal terminals in the HNS.
\end{abstract}
Key Words
$\checkmark$ angiogenesis
oxytocin
vasopressin
- endothelial cell
- plasticity
- neurosecretion

Journal of Endocrinology (2014) 222, 161-179
(C) 2014 Society for Endocrinology Printed in Great Britain
Published by Bioscientifica Ltd 


\section{Introduction}

Neurosecretion is an important issue to understand direct brain control of growth, maturation, reproduction, lactation, water homeostasis, and behaviors. In the neurohypophysis (NH), the hypothalamic neurosecretory cells secrete arginine vasopressin (AVP) and oxytocin (OXT) into the blood circulation from their axonal terminals (Miyata \& Hatton 2002). Similarly, they release a variety of neuropeptides into the blood circulation at the median eminence (ME) to control secretion of adenohypophysial hormones (Ojeda et al. 1990, 2008, Müller et al. 1999). The vasculature of adult brains generally contains the blood-brain barrier (BBB) that consists of endothelial cell sheet and tight junction and prevents free entry of blood-derived bioactive molecules into parenchyma (Engelhardt 2003, Abbott et al. 2010, Daneman et al. 2010). The neurosecretory brain regions, the $\mathrm{NH}$ and $\mathrm{ME}$, have fenestrated vasculature that has been defined as a characteristic of the lack of complete $\mathrm{BBB}$ and the direct diffusion of neuropeptides into blood circulation (Ciofi et al. 2009, Miyata \& Morita 2011, Mullier et al. 2010, Morita \& Miyata 2012, 2013).

The chronic physiological stimulations, such as osmotic and suckling ones, are well known to cause neurovascular and neuroglial reconstruction in the $\mathrm{NH}$ of adult rodents (Miyata \& Hatton 2002). Under unstimulated conditions, pituicytes or neurohypophysial astrocytes generally enclose axonal terminals, while the chronic physiological stimulations increase direct contact of axonal terminals with vascular basement membrane (Miyata et al. 2001, Miyata \& Hatton 2002). This structural reconstruction has been considered to be caused mainly by shape conversion of pituicytes via the $\beta$-adrenergic receptor (Smithson et al. 1990). Until now, however, evidence for the plasticity of neurohypophysial vasculature has not yet been reported.

In the ME, adenohypophysial hormone-releasing peptides, such as thyrotropin-releasing, corticotropinreleasing, growth hormone-releasing, and gonadotropinreleasing hormones $(\mathrm{GnRH})$, are released from axonal terminals into blood circulation (Müller et al. 1999, Prevot 2002, Prevot et al. 2010). The axonal terminals of GnRH neurons are usually separated from the basement membrane of the capillary by cellular processes of astrocytes and tanycytes in the ME (Kozlowski \& Coates 1985), while the axonal terminals of GnRH neurons and glial cells show a dynamic structural reconstruction during the estrous cycle similar to that observed in the NH (Prevot 2002, Ojeda et al. 2008, Prevot et al. 2010). These results indicate that activity-dependent structural reconstruction of neurovascular and neuroglial interaction is a common phenomenon in two neurosecretory brain regions.

Thus far, little or no attention has been given to the point for elucidating the fundamental vascular characteristic in neurosecretory brain regions, except that they lack most of the tight junction proteins and thereby possess a fenestrated feature (Norsted et al. 2008, Mullier et al. 2010, Ciofi et al. 2009, 2011, Morita \& Miyata 2012). However, we have recently shown the occurrence of vascular endothelial growth factor (VEGF)-dependent continuous angiogenesis and the expression of angiogenesis-associated proteins in the ME of adult mice (Morita et al. 2013). This study proposes that the vasculature of neurosecretory brain regions has dynamic characteristics. Angiogenesis starts at the embryonic period, persists until early the postnatal period, and then becomes quiescent along with the formation of the tight junctions (Ogunshola et al. 2000). Therefore, continuous angiogenesis is almost absent in adult mammalian brains except under pathological conditions such as injury or hypoxia (Brown \& Thore 2011). In the angiogenic vasculature, proliferation of endothelial stalk cells and filopodia extension of endothelial tip cells are principally regulated by the signaling of VEGFA and VEGF receptor 2 (VEGFR2 (KDR); Gerhardt et al. 2003, Somanath et al. 2009). The deficiency of Vegfa or Vegfr2 genes appears to be lethal due to abnormal blood vessel development (Shalaby et al. 1995, Carmeliet et al. 1996). The signaling pathway of platelet-derived growth factor $\mathrm{B}$ (PDGFB) and PDGF receptor beta (PDGFRB) is responsible for the recruitment of pericytes to new-born endothelial cells and controls the migration and shape conversion of pericytes (Lindahl et al. 1997, Fukushi et al. 2004, Winkler et al. 2011). It has been shown that the embryos of $P d g f b$ - or $P d g f r b$-deficient mice continue to develop until embryonic days 16-19, but widespread hemorrhage and edema cause embryonic lethality before birth (Lindahl et al. 1997).

Based on these observations, the objective of this study was to elucidate vascular dynamics by examining VEGF- and PDGF-dependent proliferation and apoptosis of endothelial cells and change in vascular density in the $\mathrm{NH}$ of adult mice. Moreover, we examined whether vascular reconstruction was associated with that of neurosecretory axonal terminals.

\section{Materials and methods}

\section{Animals}

This study used male mice (70-84 days old, C57BL/6J). Mice were housed in cages at a density of two per cage in a

Published by Bioscientifica Ltd 
colony room, maintained in a $12 \mathrm{~h}$ light: $12 \mathrm{~h}$ darkness cycle, and allowed to access commercial chow and tap water ad libitum. All procedures were carried out in accordance with the National Institute of Health Guidelines and the Guideline for Proper Conduct of Animal Experiments, Science Council of Japan. The experimental protocol was approved by the Animal Ethics Experimental Committee of the Kyoto Institute of Technology.

\section{Administration of tyrosine kinase inhibitors for VEGFRs and/or PDGFRs}

We used the tyrosine kinase inhibitor SU11248 for both VEGFRs and PDGFRs, AZD2171 for VEGFRs, and STI571 for PDGFRs. Mice received $0.2 \mathrm{ml}$ of the following solutions via oral gavage twice daily for 4 or 6 days: i) SU11248 (120 mg/kg per day; Carbosynth, Berkshire, UK) in vehicle (0.5\% carboxymethylcellulose, $1.8 \% \mathrm{NaCl}$, $0.4 \%$ Tween 80, and 0.9\% benzyl alcohol), ii) AZD2171 $(6 \mathrm{mg} / \mathrm{kg}$ per day, LKT Laboratories, Inc., St Paul, MN, USA) in $1 \%$ Tween 80 , and iii) STI571 (200 mg/kg per day; LKT Laboratories, Inc.) in distilled deionized water.

\section{RT-PCR}

The experiment was carried out according to the method described previously (Morita et al. 2013). After decapitation, the pituitary glands were immediately dissected out and the anterior and intermediate pituitaries were carefully removed under the microscope and stored in RNAlater RNA stabilization reagent (Qiagen). Total RNA was extracted from the $\mathrm{NH}$ of adult mice using the SV Total RNA isolation system (Promega Corporation) and then subjected to cDNA synthesis with oligo(dT) ${ }_{20}$ primers using the PC320 thermal controller (Astec, Fukuoka, Japan) and ReverTra Ace reverse transcriptase (Toyobo, Tokyo, Japan). The cDNA was subsequently amplified by PCR with the following set of primers: Vegfa, $5^{\prime}$-GCGGGCTGCCTCGCAGTC- ${ }^{\prime}$ and $5^{\prime}$-TCACCGCCTTGGCTTGTCAC-3'; Vegfr2， 5'-CTTGCAGGGGACAGCGGGAC-3' and 5'-AATCGACCCTCGGCAGGGGA-3'; Vegfr3 (Flt4), 5'-GCGACAGGGTTCTCATAA- $3^{\prime}$ and 5'-CGTTGCCTCATTGTGATTAG-3'; Pdgfra， 5'-CGACTCCAGATGG-

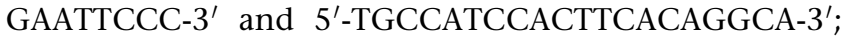
and Pdgfrb $5^{\prime}$-TGCCTCAGCCAAATGTCACC-3' and 5'-TGCTCACCACCTCGTATTCC-3'.

\section{Western blotting}

The experiments were carried out according to the method described previously (Morita et al. 2013). After decapitation, the pituitary glands of adult mice were immediately dissected out and the anterior and intermediate pituitaries were carefully removed under the microscope. The tissues were homogenized using a VCX T301B ultrasonic generator (Vibro Cell, Sonics \& Materials, Inc., Newtown, CT, USA) in a fourfold amount of PBS containing protease inhibitors at $4{ }^{\circ} \mathrm{C}$. The homogenate was dissolved in an electrophoresis sample buffer at a concentration of $1 \mathrm{mg} / \mathrm{ml}$ and boiled for $90 \mathrm{~s}$, and the protein sample was separated on SDS-polyacrylamide gel. Electroblotting was performed on the membrane (GE Healthcare Bio-Science, Buckinghamshire, UK) in a transfer buffer containing $25 \mathrm{mM}$ Tris, $192 \mathrm{mM}$ glycine, and $20 \%$ methanol. Nonspecific binding of proteins to the membrane was blocked by incubation with a 5\% ECL Prime Blocking Agent (GE Healthcare Bio-Science) in $50 \mathrm{mM}$ Tris-buffered saline containing $0.5 \%$ Tween 20 (TBST) overnight at $4{ }^{\circ} \mathrm{C}$. The membrane was incubated with the rabbit antibody against VEGF-A (Santa Cruz Biotechnology; dilution 1:500) and PDGF-B (Bioss, Inc., Woburn, MA, USA; dilution 1:1000) in TBST containing $0.2 \% \mathrm{BSA}$ for $1 \mathrm{~h}$. The membrane was further incubated with a HRP-labeled anti-rabbit IgG (dilution 1:50 000) in TBST containing 5\% BSA for $1 \mathrm{~h}$. The approximate molecular weight for each protein was estimated using Precision Plus Protein WesternC Standards and Precision Protein Strep-Tactin HRP Conjugate (Bio-Rad Laboratories; dilution 1:50 000). The peroxidase was finally visualized using an ECL Kit (ECL Prime Western blotting detection system; GE Healthcare Bio-Sciences) and the immunoreactivity was visualized employing RX-U Medical X-ray film (Fuji Film, Tokyo, Japan).

\section{Antibody}

In this study, the following primary antibodies were used for the immunohistochemistry: rabbit IgG against AVP (Millipore-Chemicon, Temecula, CA, USA; dilution 1:1000), cleaved caspase 3 (clone 5A1E; Cell Signaling, Danvers, MA, USA; dilution 1:1000), Ki-67 (Santa Cruz Biotechnology; dilution 1:1000), PDGF-B (Bioss, Inc.; dilution 1:400), VEGF-A (Santa Cruz Biotechnology; dilution 1:200), VEGFR-2 (Sigma-Aldrich Japan; dilution 1:1000), and VEGFR-3 (e-Bioscience, San Diego, CA, USA; dilution 1:100) and rat IgG against BrdU (clone BU1/75; Abcam, Cambridge, UK; dilution 1:1000), PDGFRA (clone APA5; BD Pharmingen, Qume Drive, San Jose, CA, USA; dilution 1:500), and PDGFRB (clone APB5; e-Bioscience; dilution 1:200). The following primary antibodies were used for cellular markers: Armenian hamster IgG against CD31 (endothelial cell marker, clone 2HB; DSHB; dilution 1:20); mouse IgG against glial fibrillary acidic protein (GFAP, astrocyte marker; clone G-A-5; Sigma-Aldrich Japan; dilution 1:1000), OXT-neurophysin (clone PS38; NIH, Bethesda, MD, USA, Ben-Barak et al. 1985; dilution 1:20), and AVP-neurophysin (clone PS41; NIH, Ben-Barak et al. 1985; dilution 1:20); and guinea pig polyclonal IgG against GFAP (TS-2005, Morita et al. 2010; dilution 1:500) and laminin (vascular basement membrane marker, YI-2008, Imamura et al. 2010; dilution 1:200).

\section{Immunohistochemistry for light microscopy}

Mice were perfused transcardially with PBS $(\mathrm{pH} 7.2$ ) containing $5 \mathrm{U} / \mathrm{ml}$ heparin followed by $4 \%$

Published by Bioscientifica Ltd. 
paraformaldehyde (PFA) in $0.1 \mathrm{M}$ phosphate buffer (PB, pH 7.4) after deep anesthesia with urethane. After perfusion of PFA, the pituitary glands, brains, and peripheral organs were dissected out and post-fixed with $4 \%$ PFA in $0.1 \mathrm{M} \mathrm{PB}$ (pH 7.4) overnight at $4{ }^{\circ} \mathrm{C}$. Fixed tissues were cryoprotected with $30 \%$ sucrose in PBS and frozen in the Tissue-Tek OCT compound. The sections were cut coronally on a cryostat (Leica Geosystems AG, St Gallen, Switzerland) at the thickness of $30 \mu \mathrm{m}$. A standard immunofluorescence technique was performed on free-floating sections as described in our previous paper (Mannari et al. 2014). In brief, the sections were treated with $25 \mathrm{mM}$ glycine in PBS for $20 \mathrm{~min}$ to eliminate the remaining aldehyde residues. When the mouse primary antibody was used, the sections were further treated with an unlabeled goat Fab fragment against the mouse IgG (Jackson ImmunoResearch, West Grove, PA, USA; dilution 1:400) for $2 \mathrm{~h}$ to mask endogenous mouse IgG-like proteins. After blocking with 5\% normal goat serum (NGS) in PBS containing $0.3 \%$ Triton X-100 (PBST) for $24 \mathrm{~h}$ at $4{ }^{\circ} \mathrm{C}$, they were incubated with the primary antibody for $48 \mathrm{~h}$ at $4{ }^{\circ} \mathrm{C}$. The primary rat, guinea pig, Armenian hamster, and rabbit antibodies were visualized using the Alexa 405-, 488-, or 594-conjugated secondary goat IgG antibody (Jackson ImmunoResearch; dilution 1:400). In case of the mouse primary antibody, however, Alexa 594-conjugated goat $\mathrm{F}(\mathrm{ab})_{2}$ was used (Jackson ImmunoResearch; dilution 1:100) to avoid nonspecific binding of endogenous mouse Fc receptors. The coverslips were sealed with Vectashield (Vector Labs, Burlingame, CA, USA) and observation was performed using the laser-scanning confocal LSM510 (Carl Zeiss, Oberkochen, Germany) or FV10i (Olympus) microscope. Images were saved as TIF files $(2048 \times 2048)$ and arranged using Photoshop 7.0.

For assessing the area and diameter of microvessels and the vascular area, the sections $(15 \mu \mathrm{m})$ were incubated with anti-laminin (YI-2008; dilution 1:1000) or anti-CD31 IgG (DSHB; dilution 1:100) in PBST for $48 \mathrm{~h}$ at $4{ }^{\circ} \mathrm{C}$. They were then incubated with the biotinylated secondary guinea pig or Armenian hamster IgG (Jackson ImmunoResearch; dilution 1:200) in PBST for $2 \mathrm{~h}$ followed by VECTSTAIN Elite ABC Reagent (Vector Labs; dilution 1:200) for $2 \mathrm{~h}$. Visualization of peroxidase was performed by treating the sections with $0.02 \%$ diaminobenzidine and $0.005 \% \mathrm{H}_{2} \mathrm{O}_{2}$ in $50 \mathrm{mM}$ Tris buffer ( $\mathrm{pH}$ 7.2). After the chromogen reaction, the sections were mounted onto gelatin-coated glass slides, dehydrated, and covered with Entellan Neu (Merck) and observed under an Eclipse E600 microscope (Nikon, Tokyo, Japan).

\section{Detection of proliferating and apoptotic cells}

Mice were allowed to consume water containing $\mathrm{BrdU}$ $(1 \mathrm{mg} / \mathrm{ml})$ for 6 days to examine cell proliferation under normal condition and rebound proliferation after the withdrawal of AZD2171 treatment and for 4 days to investigate the effects of VEGFR- and/or PDGFR-associated tyrosine kinase inhibitors. The pituitary glands and brains were dissected out and fixed as described above. The sections were washed with PBS, treated with $25 \mathrm{mM}$ glycine in PBS for $20 \mathrm{~min}$, and incubated with 10\% NGS in PBST for $24 \mathrm{~h}$. They were then incubated with the Armenian hamster IgG against CD31 (DSHB; dilution 1:20) or rat IgG against PDGFRA (BD Pharminogen; dilution 1:500) for $48 \mathrm{~h}$ at $4{ }^{\circ} \mathrm{C}$ and then with the Alexa 488-conjugated secondary Armenian hamster or rat IgG (Jackson ImmunoResearch; dilution 1:200) in PBST for $2 \mathrm{~h}$. For the detection of $\mathrm{BrdU}$, the sections were pretreated with $2 \mathrm{M} \mathrm{HCl}$ at $37^{\circ} \mathrm{C}$ for $30 \mathrm{~min}$ and then neutralized with $0.1 \mathrm{M}$ borate buffer ( $\mathrm{pH} 8.4$ ) for $20 \mathrm{~min}$. They were incubated with the rat anti-BrdU IgG (Abcam; dilution 1:1000) in PBST containing 5\% NGS for $48 \mathrm{~h}$ at $4{ }^{\circ} \mathrm{C}$. The sections were then incubated with the Alexa 594conjugated anti-rat IgG (Jackson ImmunoResearch; dilution 1:400) in PBST for $2 \mathrm{~h}$. For visualization of nuclei, the sections were incubated with propidium iodide (Sigma-Aldrich Japan; $40 \mu \mathrm{g} / \mathrm{ml}$ ).

For the immunohistochemistry of Ki-67 and caspase 3, the sections were incubated with the Armenian hamster IgG against CD31 (DSHB; dilution 1:20) for $48 \mathrm{~h}$ at $4{ }^{\circ} \mathrm{C}$ followed by the Alexa 488-conjugated secondary Armenian hamster IgG (Jackson ImmunoResearch; dilution 1:200) in PBST for $2 \mathrm{~h}$. They were then treated with $0.05 \%$ citraconic anhydride solution (Immunosaver; Nissin EM Co. Ltd, Tokyo, Japan) for $30 \mathrm{~min}$ at $95^{\circ} \mathrm{C}$ according to the previous study (Namimatsu et al. 2005). In the case for Ki-67, the sections were further treated with $2 \mathrm{~N} \mathrm{HCl}$ for $20 \mathrm{~min}$ at $37^{\circ} \mathrm{C}$. After blocking with 5\% NGS for $24 \mathrm{~h}$ at $4{ }^{\circ} \mathrm{C}$, the sections were incubated with the rabbit IgG against Ki-67 (Santa Cruz Biotechnology; dilution 1:1000) or cleaved caspase 3 (Cell Signaling; dilution 1: 1000) for $48 \mathrm{~h}$ at $4{ }^{\circ} \mathrm{C}$. The sections were then incubated with the Alexa 594-conjugated anti-rat IgG or Alexa 488-conjugated anti-rabbit IgG (Jackson ImmunoResearch; dilution 1:400) in PBST for $2 \mathrm{~h}$.

\section{Quantitative and statistical analyses}

For the quantitative analysis, confocal images were obtained under the same pinhole size, brightness, and contrast setting. The images $(1024 \times 1024$ pixels $)$ were saved as TIF files by employing LSM510 Image Browser (Carl Zeiss) or FV10-ASW Ver 1.7 Viewer (Olympus) for Windows, and arranged using Photoshop 7.0. For the quantitative analysis, BrdU- and PI-labeled nuclei were carefully identified by three-dimensional (3D) images (interval of optical slice at $1 \mu \mathrm{m}$ ). The number of BrdU-labeled endothelial cells, oligodendrocyte progenitor cells (OPCs), and CD31immunoreactive endothelial cells, and the area of the laminin-positive vasculature and AVP- and OXT-immunoreactive axonal terminals were counted using WinRoof (Mitani Corporation, Fukui, Japan) for which the threshold intensity was set to be included for measurement profile by visual inspection and kept constant.

For assessing the area and diameter of microvessels, images of CD31 and laminin immunoreactivity visualized

Published by Bioscientifica Ltd 
with chromogen were obtained using the Eclipse E600 microscope (Nikon), saved as TIF files $(1024 \times 1024$ pixels), and arranged using Photoshop 7.0. The area of the CD31-positive endothelial cells and the laminin-positive vasculature and the total area were measured using WinRoof, for which the threshold intensity was set to be included for measurement profile (only immunoreactive) by visual inspection and kept constant. The diameter of microvessels was manually measured at $10 \mu \mathrm{m}$ interval and their mean diameter was obtained. Analysis of all images was performed such that the experimenter was blind to the treatment group. Statistical difference was assessed using a significance level of $P<0.05$ by unpaired Student's $t$-test or ANOVA with Tukey's post hoc test.

\section{Results}

\section{Proliferation of endothelial cells}

We performed BrdU and Ki-67 immunohistochemistry to detect proliferating cells in the NH of adult mice. Doublelabeling immunohistochemistry of BrdU and a vascular basement membrane marker laminin revealed that many BrdU-positive nuclei were observed at the neurohypophysial vasculature after administration of BrdU for 6 days (Fig. 1A). Analysis of the 3D image revealed the presence of a BrdU-labeled nucleus at the neurohypophysial vasculature (Fig. 1B). Double-labeling immunohistochemistry of BrdU and an endothelial cell marker CD31 revealed that BrdU-labeled nuclei were often seen at endothelial cells and parenchyma cells (Fig. 1C). The number of BrdUlabeled endothelial cells (mean number of BrdU-labeled cells \pm s.E.M. $/ \mathrm{mm}^{2}$ ) was $131.66 \pm 19.84$ in the $\mathrm{NH}$ after administration of BrdU for 6 days. It has been shown that proliferating parenchyma cells are OPCs that differentiate into pituicytes in the NH of adult rats (Virard et al. 2008). Analysis of the 3D image revealed the presence of a BrdU-labeled nucleus within an endothelial cell (Fig. 1D). Double-labeling immunohistochemistry showed the presence of Ki-67-positive nuclei in CD31-positive endothelial cells (Fig. 1E). The expression of Ki-67 (MKI67) is strictly associated with all active phases of the cell cycle $\left(G_{1}, S, G_{2}\right.$, and mitosis), but absent from resting cells $\left(G_{0}\right)$. Analysis of the 3D image showed the presence of a Ki-67-positive nucleus within a CD31-positive endothelial cell (Fig. 1F).

\section{Expression of VEGFA and VEGFRs}

VEGFA and VEGFRs are principal signaling pathways for proliferation of endothelial cells in the developing vasculature (Gerhardt et al. 2003, Mackenzie \& Ruhrberg 2012).
The immunohistochemistry showed that the expression of VEGFA was higher in the $\mathrm{NH}$ of adult mice when compared with that of the anterior and intermediate pituitaries (Fig. 2A). Double-labeling immunohistochemistry of VEGFA and a pituicyte marker GFAP revealed that many VEGFA-immunoreactive puncta were seen at pituicytes (Fig. 2B). RT-PCR analysis revealed the expression of $V e g f a_{120}$ but not $V e g f a_{164}$ and $V e g f a_{188}$ mRNA in the NH (Fig. 2C). Western blotting further confirmed the predominant expression of the mature form of $\mathrm{VEGFA}_{120}$ by judging from their molecular mass (Fig. 2C). Triple-labeling immunohistochemistry of VEGFR2, CD31, and laminin revealed that VEGFR2 was expressed specifically in endothelial cells in the neurohypophysial vasculature (Fig 2D). RT-PCR analysis further showed the expression of Vegfr 2 mRNA in the $\mathrm{NH}$ of adult mice (Fig 2E). Double-labeling immunohistochemistry showed that VEGFR3 was expressed in AVP(Fig. 2H) and OXT-containing (data not shown) axonal terminals and pituicytes (Fig. 2I) but not in endothelial cells (Fig. 2F). RT-PCR analysis showed the expression of Vegfr3 mRNA in the NH of adult mice (Fig. 2G).

\section{Expression of PDGFB and PDGFRs}

PDGFB and PDGFRB are generally highly expressed in endothelial cells and pericytes in the developing vasculature and mediate the interaction between endothelial cells and pericytes and the migration and shape conversion of pericytes (Lindahl et al. 1997, Fukushi et al. 2004, Daneman et al. 2010). Triple-labeling immunohistochemistry revealed that PDGFB was localized to OXTcontaining axonal terminals but not to CD31-positive endothelial cells (Fig. 3A). The immunoreactivity of PDGFB was observed as numerous puncta within OXTcontaining axonal terminals (Fig. 3C) but not in the AVP-containing ones (Fig. 3B). High-magnification views showed the localization of PDGFB to neurosecretory granules of OXT-containing axonal terminals (Fig. 3D). Western blotting confirmed the expression of PDGFB in the $\mathrm{NH}$ of adult mice (Fig. 3E). It has been demonstrated that PDGFRA-positive OPCs differentiate into pituicytes in the NH (Virard et al. 2008). Double-labeling immunohistochemistry of PDGFRA and a pituicyte marker GFAP revealed that the expression of PDGFRA in pituicytes was at an undetectable level (Fig. 3F). RT-PCR analysis further indicated the expression of Pdgfra mRNA from neurohypophysial cDNA of adult mice (Fig. 3G). Double immunolabeling of PDGFRB and a pericyte marker desmin revealed that the expression of PDGFRB was

Published by Bioscientifica Ltd. 

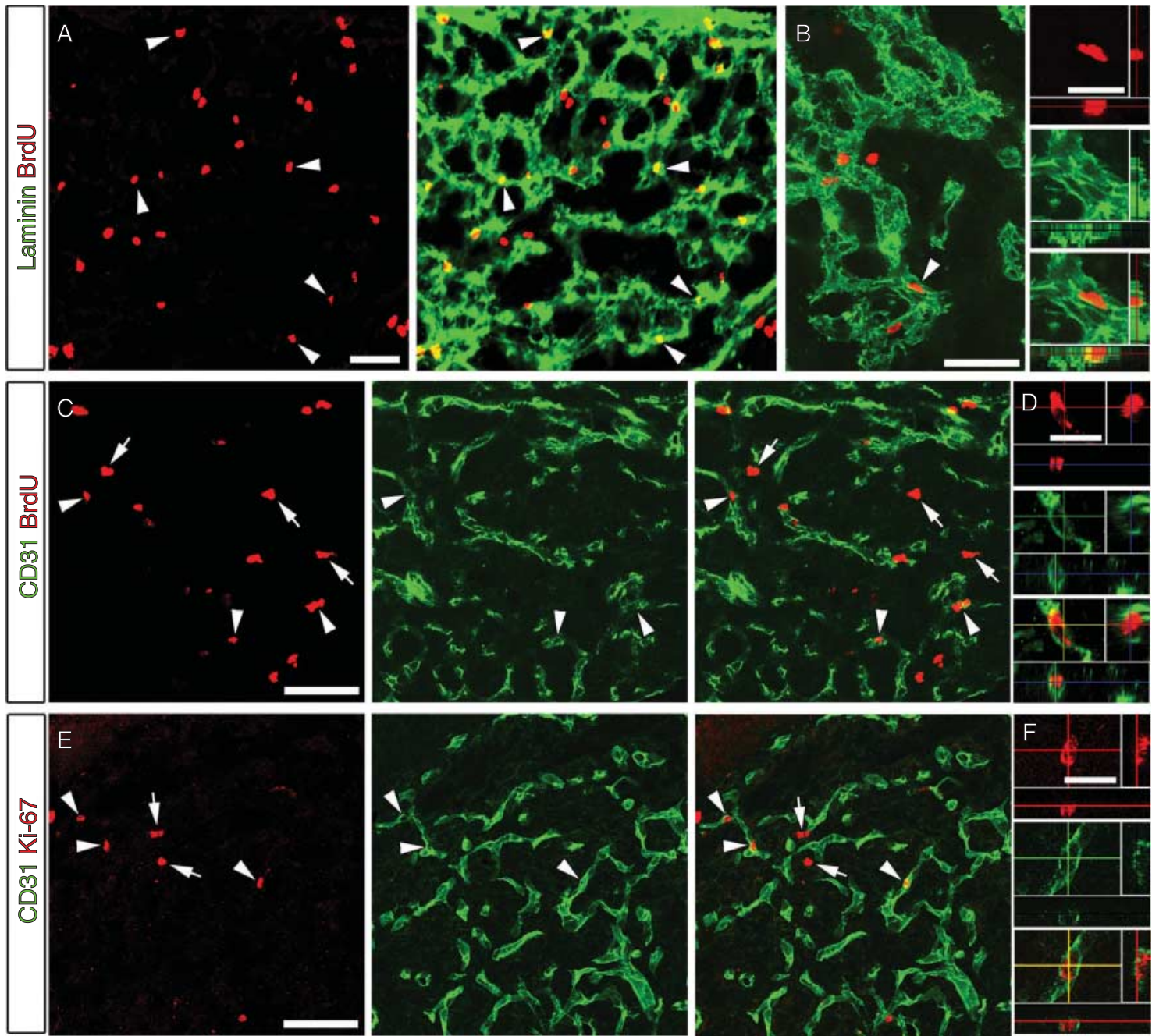

\section{Figure 1}

Proliferation of endothelial cells in the NH of adult mice. Proliferating cells were detected by the immunohistochemistry of BrdU and Ki-67. For BrdUlabeling, mice were allowed to consume water containing BrdU $(1 \mathrm{mg} / \mathrm{ml})$ for 6 days. (A and B) Confocal images revealing that BrdU-labeled nuclei were frequently seen in the laminin-positive vasculature (arrowheads in (A)). Analysis of the 3D image revealed the presence of the BrdU-labeled nucleus within the laminin-positive vasculature (arrowhead in (B)). (C and D) Double-labeling immunohistochemistry with an endothelial cell marker CD31 showed that BrdU-labeled nuclei were frequently seen

specific at pericytes (Fig. 3H). RT-PCR analysis further indicated the expression of Pdgfrb mRNA in the $\mathrm{NH}$ of adult mice (Fig. 3I).

\section{Effects of tyrosine kinase inhibitor for VEGFRs and/or PDGFRs on proliferation of endothelial cells and OPCs}

Administration of the tyrosine kinase inhibitor SU11248 for both VEGFRs and PDGFRs, AZD2171 for VEGFRs, and STI571 for PDGFRs apparently decreased the number of in endothelial cells (arrowheads in (C)) and CD31-negative parenchyma cells (arrows in (C)). Analysis of the 3D image revealed the presence of the BrdU-labeled nucleus within a CD31-positive endothelial cell (D). (E and F) Ki-67-immunoreactive nuclei were detected in CD31-positive endothelial cells (arrowheads in (E)) and CD31-negative parenchyma cells (arrows in (E)). Analysis of the 3D image confirmed the presence of the Ki-67-positive nucleus within a CD31-positive endothelial cell (F). Scale bars represent $10 \mu \mathrm{m}(\mathrm{B}, \mathrm{D}$ and $\mathrm{F})$ and $50 \mu \mathrm{m}(\mathrm{A}, \mathrm{C}$ and $\mathrm{E})$.

BrdU-labeled endothelial cells when compared with the control (Fig. 4A). Similarly, administration of AZD2171 decreased the number of BrdU-labeled OPCs when compared with the control (Fig. 4B). The quantitative analysis revealed that treatment with SU11248 significantly decreased the number of BrdU-labeled endothelial cells (\% of control: $5.62 \pm 1.35, P=0.00037$ by ANOVA with Turkey's post hoc tests, $n=4)$ and OPCs $(12.91 \pm 1.54, P=0.00049)$ when compared with that of the control (Fig. 4C). Administration of AZD2171 significantly decreased the number of

Published by Bioscientifica Ltd. 

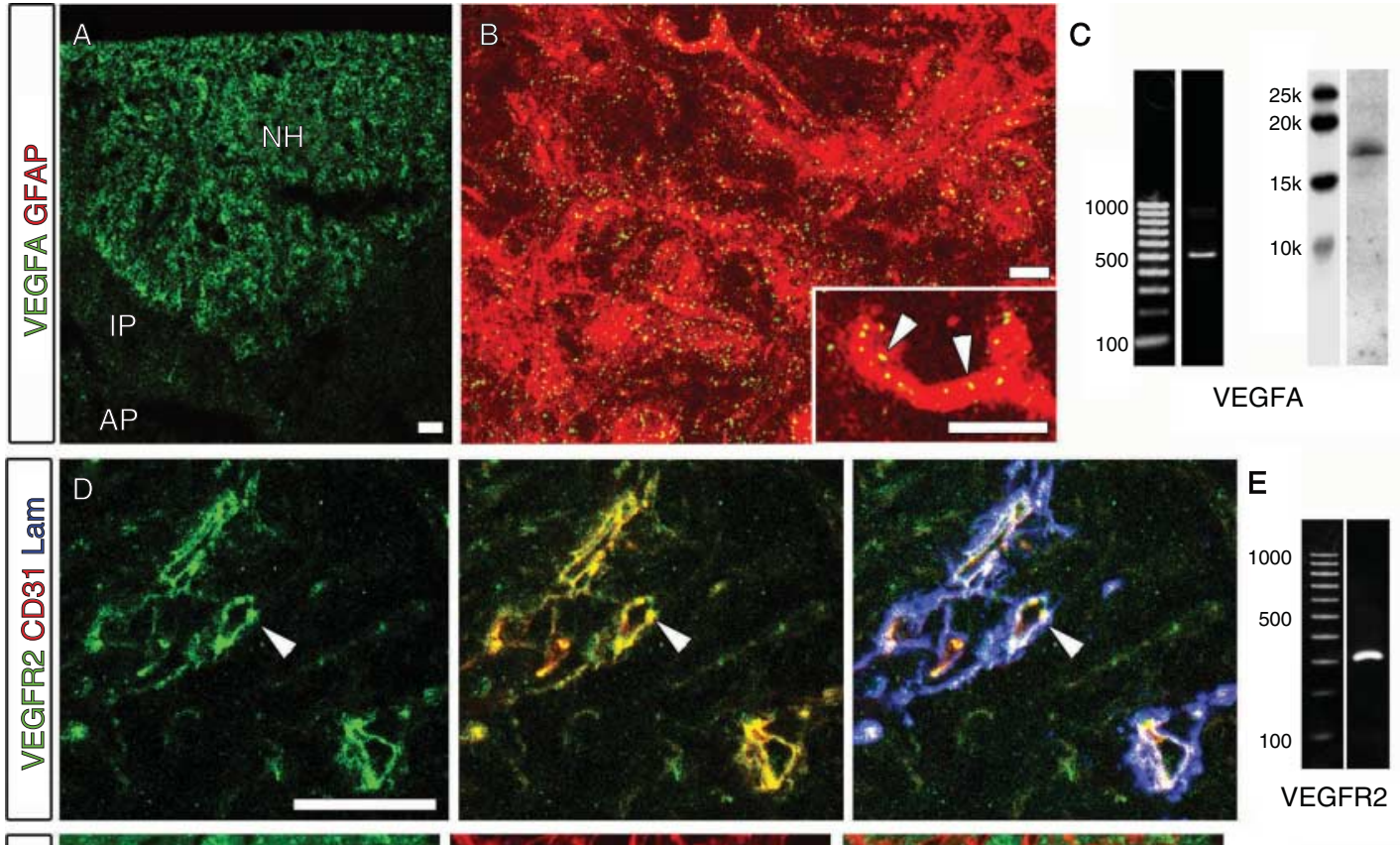

$E$
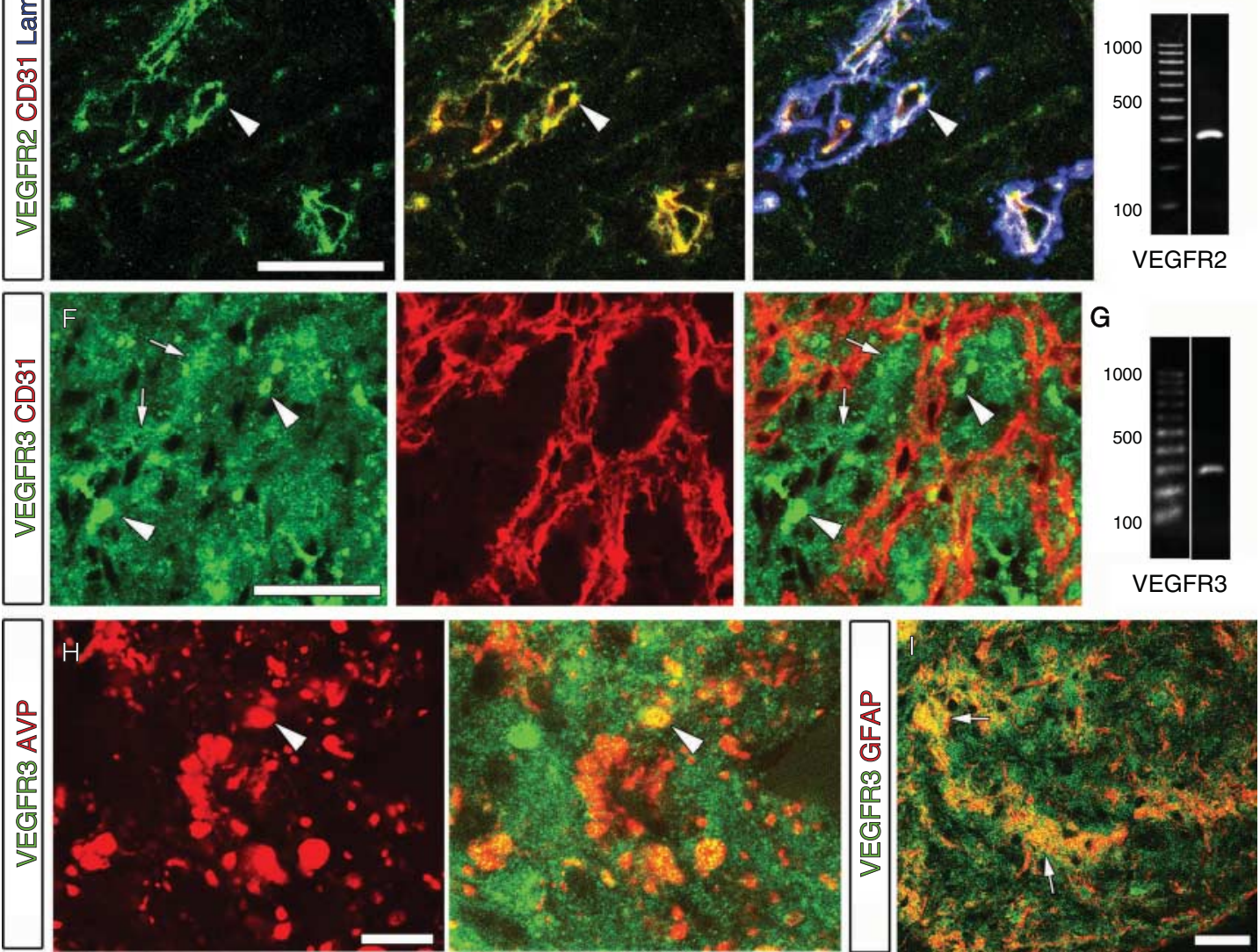

\section{Figure 2}

The localization of VEGFA and VEGFRs in the NH of adult mice. (A, B and C) The immunoreactivity of VEGFA was prominently higher in the NH when compared with that of the anterior and intermediate pituitary (A). There were many VEGFA-immunoreactive puncta in GFAP-positive pituicytes (arrowheads at inset of (B)). RT-PCR analysis showed a prominent signal at a band corresponding to Vegfa ${ }_{120}$ mRNA (512 bp) but not Vegf-f- $A_{188}$ (716 bp) and $V_{e g f a}{ }_{164}(644 \mathrm{bp})$ mRNAs from neurohypophysial cDNA (C). A mature form of VEGFA 120 was detected with a molecular weight of $18 \mathrm{kDa}$ by western blotting (C). (D and E) The immunoreactivity of VEGFR2

BrdU-labeled endothelial cells $(1.5 \mathrm{mg}, 30.05 \pm 10.54$, $P=0.0072 ; 3 \mathrm{mg}, 38.42 \pm 5.66, P=0.0066$; and $6 \mathrm{mg}$, $4.33 \pm 1.11, P=0.00024)$ when compared with that of the control. Similarly, treatment with AZD2171 significantly was observed specifically in CD31-positive endothelial cells of the vasculature (arrowheads in (D)). RT-PCR analysis revealed a specific signal corresponding to the predicted size (314 bp) of Vegfr2 mRNA (E). (F, G, $\mathrm{H}$ and I) The immunoreactivity of VEGFR3 was observed in axonal terminals (arrowheads in (F) and (H)) and GFAP-positive pituicyte (arrows in (F) and (I)). RT-PCR analysis revealed a specific signal corresponding to the predicted size (290 bp) of Vegfr3 mRNA (G). AP, anterior pituitary; IP, intermediate pituitary; Lam, laminin. Scale bars represent $10 \mu \mathrm{m}$ (insert in (B)) and $50 \mu \mathrm{m}$ ( $A, B, D, F, H$ and $I)$.

decreased the number of BrdU-labeled OPCs $(1.5 \mathrm{mg}$, $44.07 \pm 12.17, P=0.034 ; 3 \mathrm{mg}, 46.92 \pm 3.82, P=0.018$; and $6 \mathrm{mg}, 28.21 \pm 2.59, P=0.011)$ when compared with that of the control. Administration of STI571 significantly

Published by Bioscientifica Ltd. 

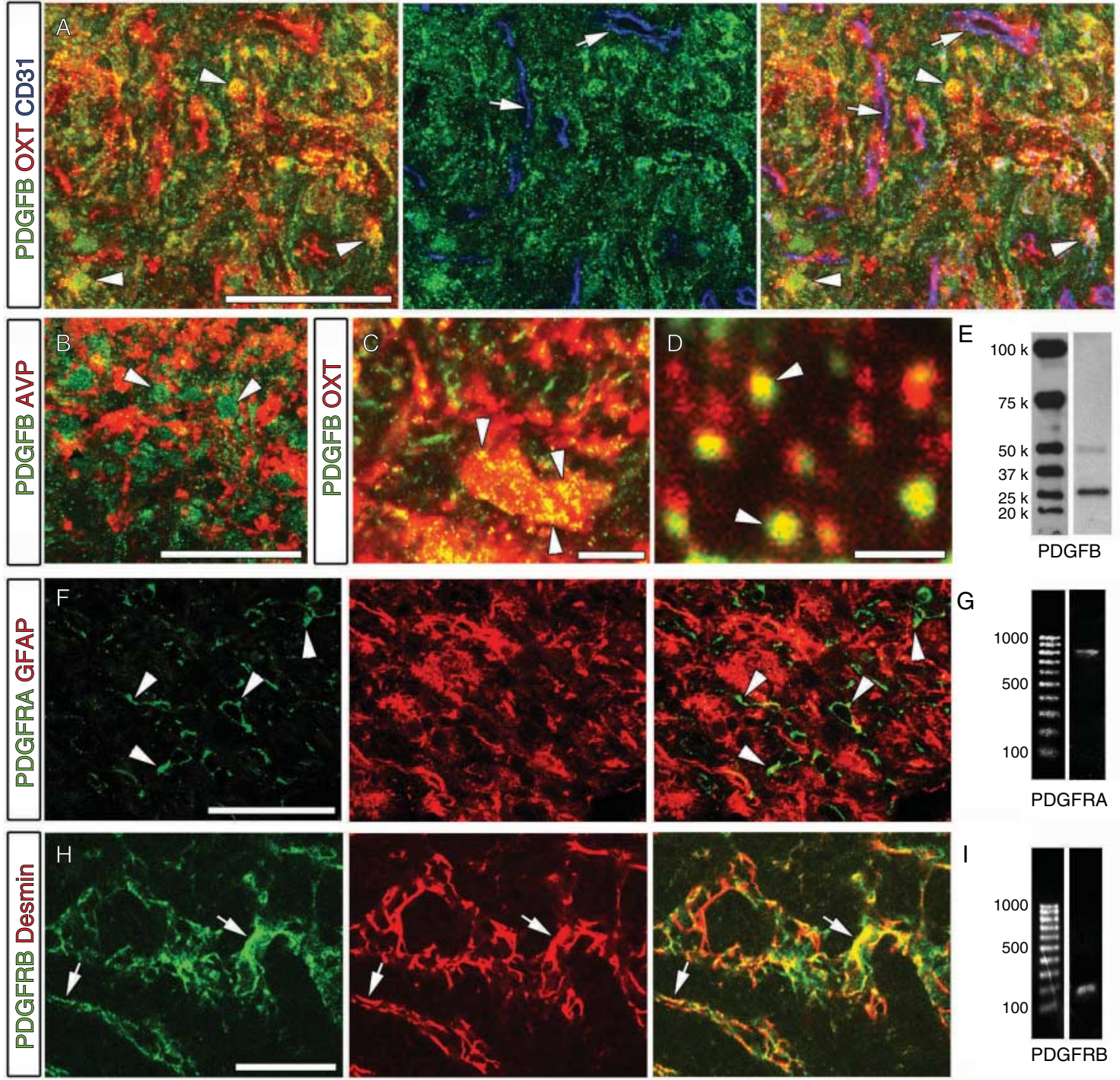

Figure 3

The localization of PDGFB and PDGFRs in the NH of adult mice. (A, B, C, D and E) The immunoreactivity of PDGFB was observed in OXT-containing axonal terminals (arrowheads in (A)) but not AVP-containing axonal terminals (B) and CD31-positive endothelial cells (arrows in (A)). A high-magnification view showed that the immunoreactivity of PDGFB was observed within neurosecretory granules of OXT-containing axonal terminals ( $C$ and $D$ ). Western blotting showing a prominent signal of PDGFB with a molecular weight of $24 \mathrm{kDa}$ and faint signal of PDGFB with a molecular weight of

decreased the number of BrdU-labeled endothelial cells $(34.77 \pm 6.21, \quad P=0.0049)$ and OPCs $(20.78 \pm 2.70$, $P=0.00096)$ when compared with that of the control.

\section{Rebound proliferation of endothelial cells after the withdrawal of VEGFR signaling inhibition}

To examine the reversibility of cellular proliferation decreased by VEGFR signaling inhibition, mice received
$48 \mathrm{kDa}(\mathrm{E})$. ( $\mathrm{F}$ and G) The immunoreactivity of PDGFRA (arrowheads in (F)) was not observed in GFAP-positive pituicytes. RT-PCR analysis revealed a specific signal corresponding to the predicted size (823 bp) of Pdgfra mRNA (G). ( $F$ and $G$ ) Double-labeling immunohistochemistry using a pericytes marker desmin revealed that the immunoreactivity of PDGFRB was specifically observed in pericytes (arrows in (H)). RT-PCR analysis revealed a specific signal corresponding to the predicted size (162 bp) of Pdgfrb mRNA (I). Scale bars represent $500 \mathrm{~nm}(\mathrm{D}), 10 \mu \mathrm{m}(C)$, and $50 \mu \mathrm{m}(\mathrm{A}, \mathrm{B}, \mathrm{F}$ and H).

oral administration of AZD2171 (6 mg/kg per day) for 6 days and then kept without AZD2171 treatment for 6 days. Double-labeling immunohistochemistry revealed that BrdU-labeled endothelial cells were conspicuously increased after the withdrawal of AZD2171 treatment when compared with the control (Fig. 5A and B). BrdUlabeled endothelial cells often lay close to the same line of the microvessel (Fig. 5A and B). The quantitative analysis showed that the number of BrdU-labeled

Published by Bioscientifica Ltd. 

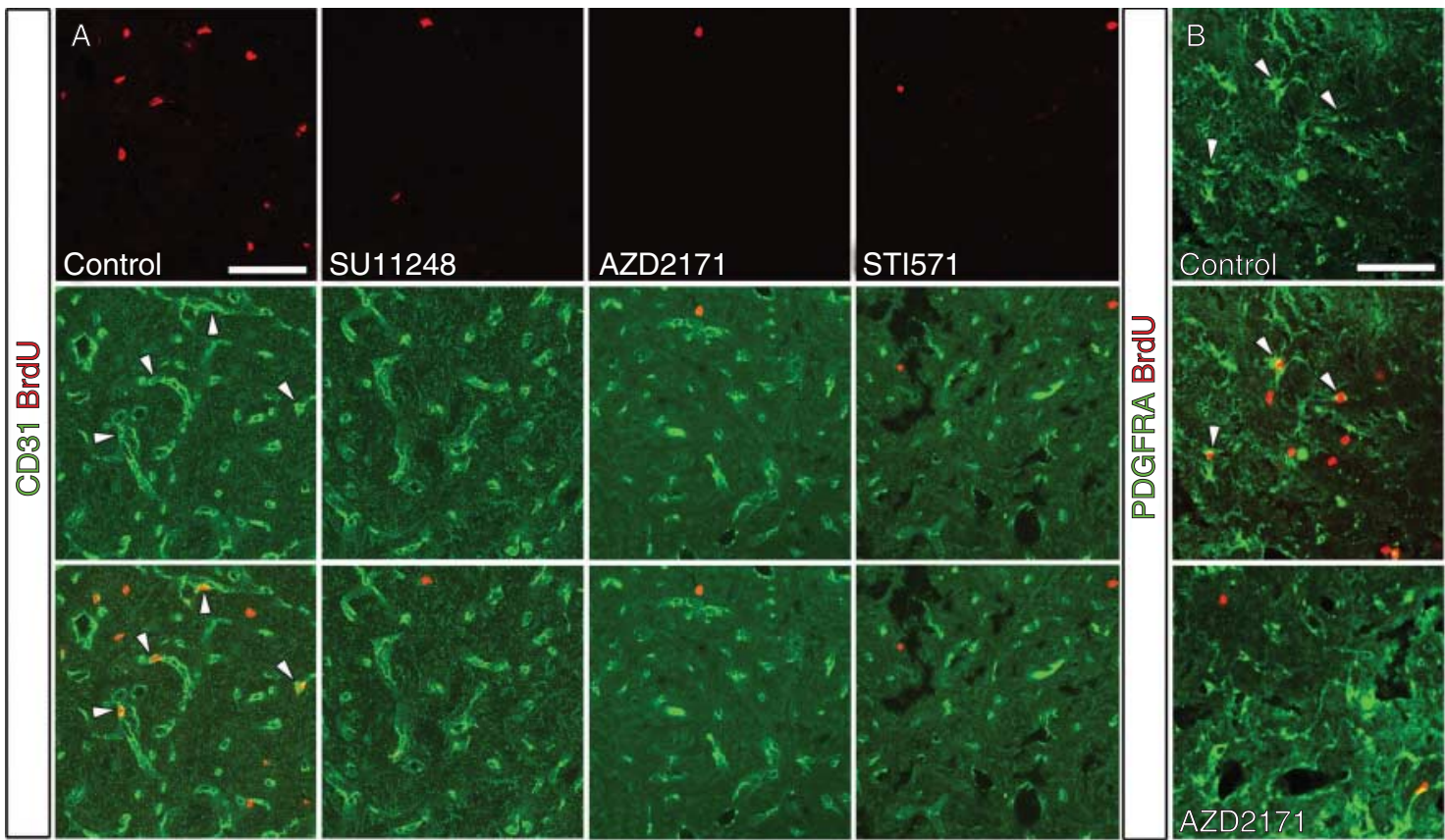

C
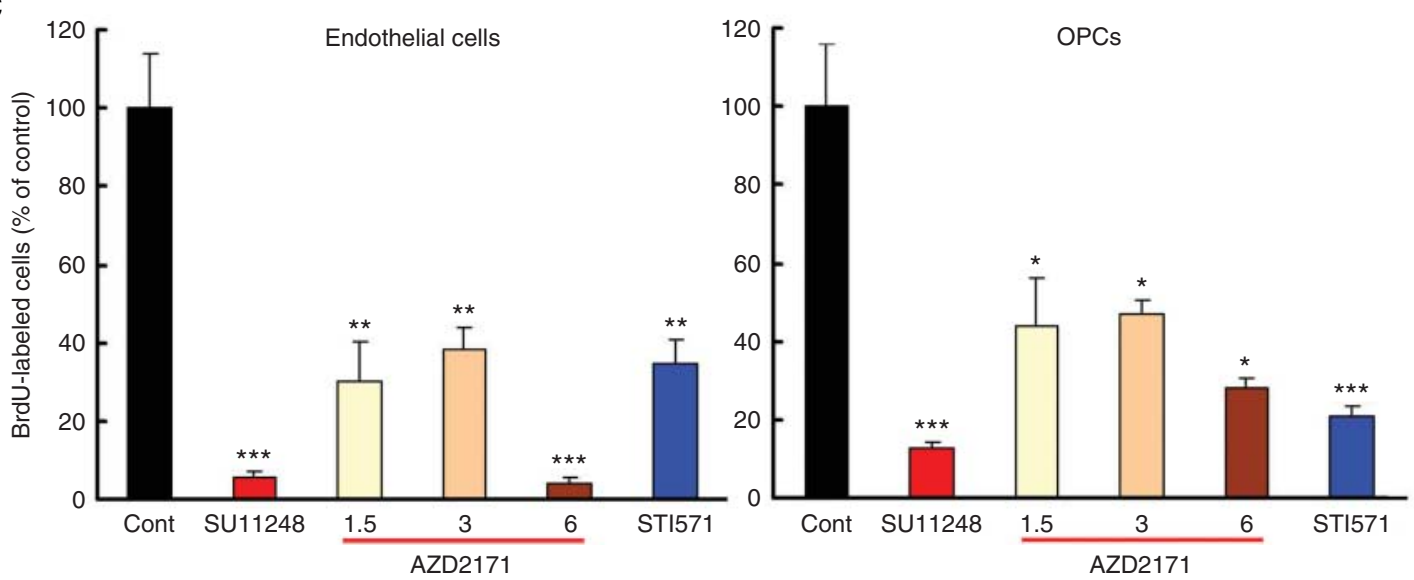

\section{Figure 4}

The effects of tyrosine kinase inhibitors for VEGFRs and/or PDGFRs on proliferation of endothelial cells and OPCs in the $\mathrm{NH}$ of adult mice. Animals received oral administration of the tyrosine kinase inhibitor SU11248 for both VEGFRs and PDGFRs, AZD2171 for VEGFRs, and STI571 for PDGFRs together with drinking of BrdU-containing water $(1 \mathrm{mg} / \mathrm{ml})$ for 4 days.

( $A$ and $B$ ) There were many BrdU-labeled endothelial cells (arrowheads in (A)) and OPCs (arrowheads in (B)) in the NH of control mice, but treatment with SU11248 (120 mg/kg per day), AZD2171 (6 mg/kg per day), and STI571
(200 mg/kg per day) largely diminished BrdU-labeled endothelial cells and OPCs. Scale bars represent $50 \mu \mathrm{m}$. (C) The quantitative analysis showed that the number of BrdU-labeled endothelial cells and OPCs was significantly decreased by treatment with SU11248 $(120 \mathrm{mg} / \mathrm{kg}$ per day), AZD2171 $(1.5,3$, and $6 \mathrm{mg} / \mathrm{kg}$ per day), and STI571 (200 mg/kg per day) when compared with that of the vehicle control. Data are expressed as mean \pm S.E.M., $n=4, * P<0.05, * * P<0.01$, and $* * * P<0.001$ vs the control by ANOVA using Turkey's post hoc tests. endothelial cells was 10.59 times higher in AZD2171treated mice $(P=0.00000015$ by unpaired Student's $t$-test, $n=5$ ) when compared with the control (Fig. 5C). By contrast, administration of AZD2171 significantly $(P=0.017)$ decreased the number of BrdU-labeled OPCs by $33.0 \%$ when compared with the control. The basal proliferation of endothelial cells was significantly lower Printed in Great Britain in the somatosensory cortex (number of BrdU-labeled cells $/ \mathrm{mm}^{2} ; 0.71 \pm 0.14, P=0.00035$ by Student's $t$-test) when compared with the NH $(131.66 \pm 19.84)$. Proliferation of endothelial cells was not significantly changed in the somatosensory cortex $(0.47 \pm 0.13, P>0.05)$ after the withdrawal of AZD2171 treatment when compared with the control. 


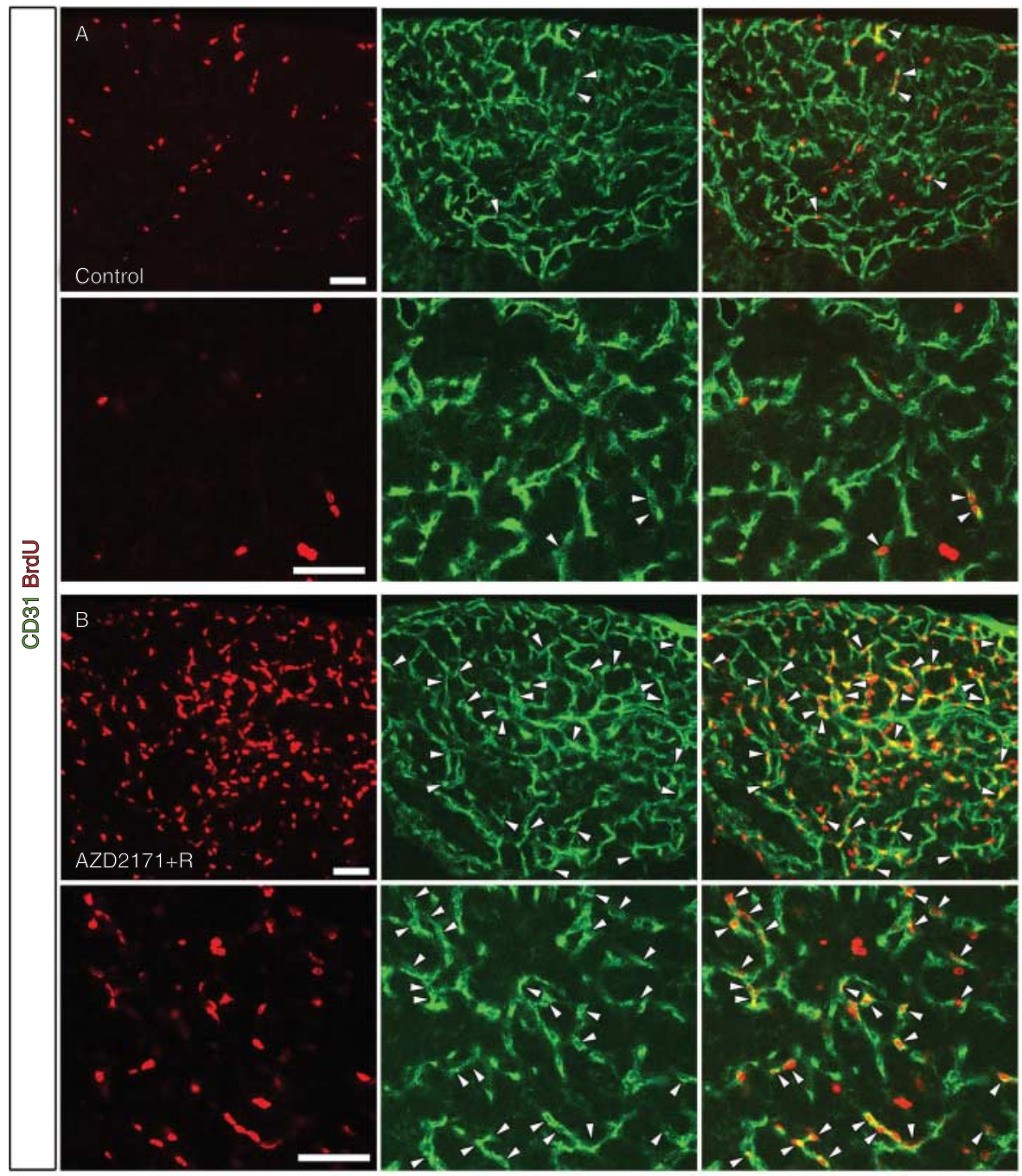

C

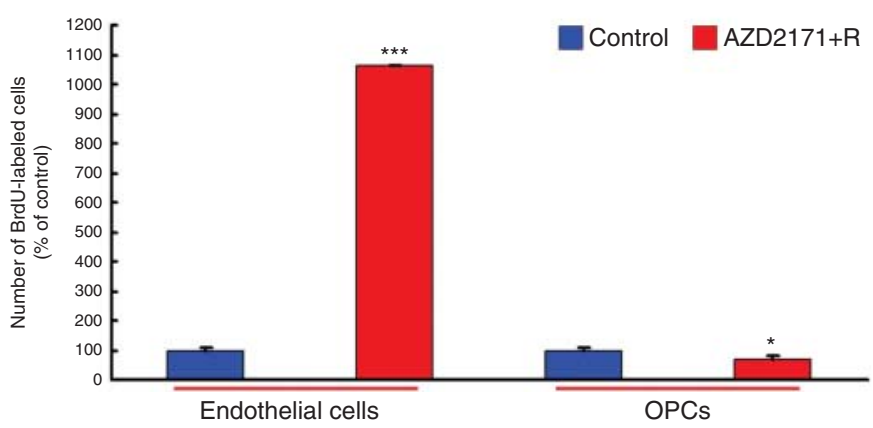

\section{Figure 5}

Dramatic rebound proliferation of endothelial cells but not OPCs after the withdrawal of the VEGFR-associated tyrosine kinase inhibitor AZD2171 treatment in the $\mathrm{NH}$ of adult mice. Mice received oral administration of the tyrosine kinase inhibitor AZD2171 (6 mg/kg per day) or vehicle for 6 days and then were kept without AZD2171 treatment for 6 days. After the withdrawal of AZD2171 treatment, animals were allowed to consume BrdU-containing water $(1 \mathrm{mg} / \mathrm{ml})$ for 6 days. (A and B) A large number of BrdU-labeled endothelial cells were observed after the withdrawal of 6-day administration of AZD2171 when compared with the control. Arrowheads Printed in Great Britain indicate BrdU-labeled endothelial cells. Scale bars represent $50 \mu \mathrm{m}$. (C) The quantitative analysis showed that the number of BrdU-labeled endothelial cells was significantly increased after the withdrawal of 6-day administration of AZD2171 when compared with the control. By contrast, the number of BrdU-labeled OPCs was significantly lower after the withdrawal of 6-day administration of AZD2171 than the control. AZD2171+R, 6-day recovery after the withdrawal of AZD2171 treatment. Data are expressed as mean \pm s.E.M., $n=4, * P<0.05$ and $* * * P<0.001$ vs the control by unpaired Student's $t$-test.

Published by Bioscientifica Ltd. 


\section{Effects of VEGFR and PDGFR signaling inhibition on vascular structure}

The vascular structure of the $\mathrm{NH}$ is unique, as endothelial cells are surrounded by a large perivascular space consisting of two layers of the basement membrane (Morita \& Miyata 2012). Double-labeling immunohistochemistry showed that CD31-positive endothelial cells were covered by a large laminin-positive perivascular space (Fig. 6A). High-magnification views showed that the inner basement membrane covered endothelial cells and the outer basement membrane enveloped the large perivascular space (Fig. 6B). Administration of the VEGFassociated tyrosine kinase inhibitor AZD2171 significantly decreased the area of CD31-positive endothelial cells (Fig. 6C) and the laminin-positive vasculature (Fig. 6D) when compared with the control. AZD2171 also decreased the number of CD31-positive endothelial cells when compared with the control (Fig. 6E). The quantitative analysis revealed that AZD2171 significantly decreased the area of CD31-positive endothelial cells (\% of CD31immunoreactive area/total area: control, $23.39 \pm 1.60$ and AZD2171, $15.44 \pm 1.06 ; P=0.0059$ by ANOVA with Turkey's post hoc tests, $n=5$; Fig. 6 F). Administration of AZD2171 significantly reduced the density of CD31positive endothelial cells (\% of control: control, 100.00 \pm 1.48 and AZD2171, 79.92 $\pm 0.69 ; P=0.00000083$; Fig. 6F). Treatment with AZD2171 did not change $(P>0.05)$ the diameter of CD31-positive microvessels (Fig. 6F). Treatment with AZD2171 significantly decreased the area of the laminin-positive vasculature (\% of laminin-immunoreactive area/total area: control, $54.06 \pm 1.74$ and AZD2171, $46.83 \pm 0.60 ; P=0.0000062)$ when compared with that of the control (Fig. 6F). The area and number of CD31-positive endothelial cells and the area of the laminin-positive vasculature returned to control levels 6 days after the withdrawal of AZD2171 treatment. Administration of AZD2171 did not significantly $(P>0.05)$ change the area of CD31-positive endothelial cells in the anterior pituitary, the somatosensory cortex, the kidney, the liver, the adrenal cortex, and the adrenal medulla (Fig. 6G).

In contrast to AZD2171, administration of the PDGFassociated tyrosine kinase inhibitor STI571 did not significantly $(P>0.05)$ change the area of CD31-positive endothelial cells (Fig. 7A and B) and the laminin-positive vasculature (Fig. 7C and D) when compared with the control. The withdrawal of STI571 treatment slightly increased the number of BrdU-labeled OPCs (control, $100 \pm 15.07$ and STI571, $152.28 \pm 5.31 ; P=0.018$ by unpaired Student's $t$-test, $n=4$ ), but did not significantly
$(P=0.05)$ change the number of BrdU-labeled endothelial cells (Fig. 7E, F and G).

\section{Effects of VEGF signaling inhibition on apoptosis of endothelial cells}

We examined the effects of AZD2171 on the expression of an apoptosis marker caspase 3 in endothelial cells to demonstrate that the decrease in vascular density caused by VEGFR signaling inhibition is due to the apoptosis of endothelial cells. Mice received oral administration of AZD2171 (6 mg/kg per day) for 1, 2, and 3 days and were then fixed for the immunohistochemistry of cleaved caspase 3. Double-labeling immunohistochemistry revealed that caspase 3-positive endothelial cells were more often seen after administration of AZD2171 when compared with the control (Fig. 8A, B, C and D). Highmagnification views revealed continuous distribution of caspase 3-positive endothelial cells in the same microvessel (Fig. 8E, F, G and H). The quantitative analysis showed that the number of caspase 3-positive endothelial cells was 5.26 times on day 1 ( $P=0.01309$ by ANOVA with Turkey's post hoc tests, $n=4), 4.97$ times on day $2(P=0.02121)$, and 6.70 times on day $3(P=0.001314)$ in AZD2171-treated mice when compared with the control (Fig. 8I).

\section{Effects of VEGFR and PDGFR signaling inhibition on the density of AVP- and OXT-containing axonal terminals}

We examined the effects of AZD2171 and STI571 on the density of AVP- and OXT-immunoreactive axonal terminals to demonstrate that inhibition of VEGFR and PDGFR signaling causes reconstruction of AVP- and OXTcontaining axonal terminals. Mice received oral administration of AZD2171 (6 mg/kg per day) or STI571 (200 mg/kg per day) for 6 days and were then fixed for the immunohistochemistry. Double-labeling immunohistochemistry revealed that OXT-immunoreactive axonal terminals were more likely to localize in close proximity to the vasculature than the AVP-containing ones in control animals (Fig. 9A and D). The number of AVP-immunoreactive axonal terminals was decreased after treatment with AZD2171 (Fig. 9B) and STI571 (Fig. 9C) when compared with the control (Fig. 9A). The number of OXTimmunoreactive axonal terminals was decreased by treatment with AZD2171 (Fig. 9E), but not STI571 (Fig. 9F), when compared with the control (Fig. 9D).

The quantitative analysis revealed that treatment with AZD2171 significantly decreased the density of both

Published by Bioscientifica Ltd 

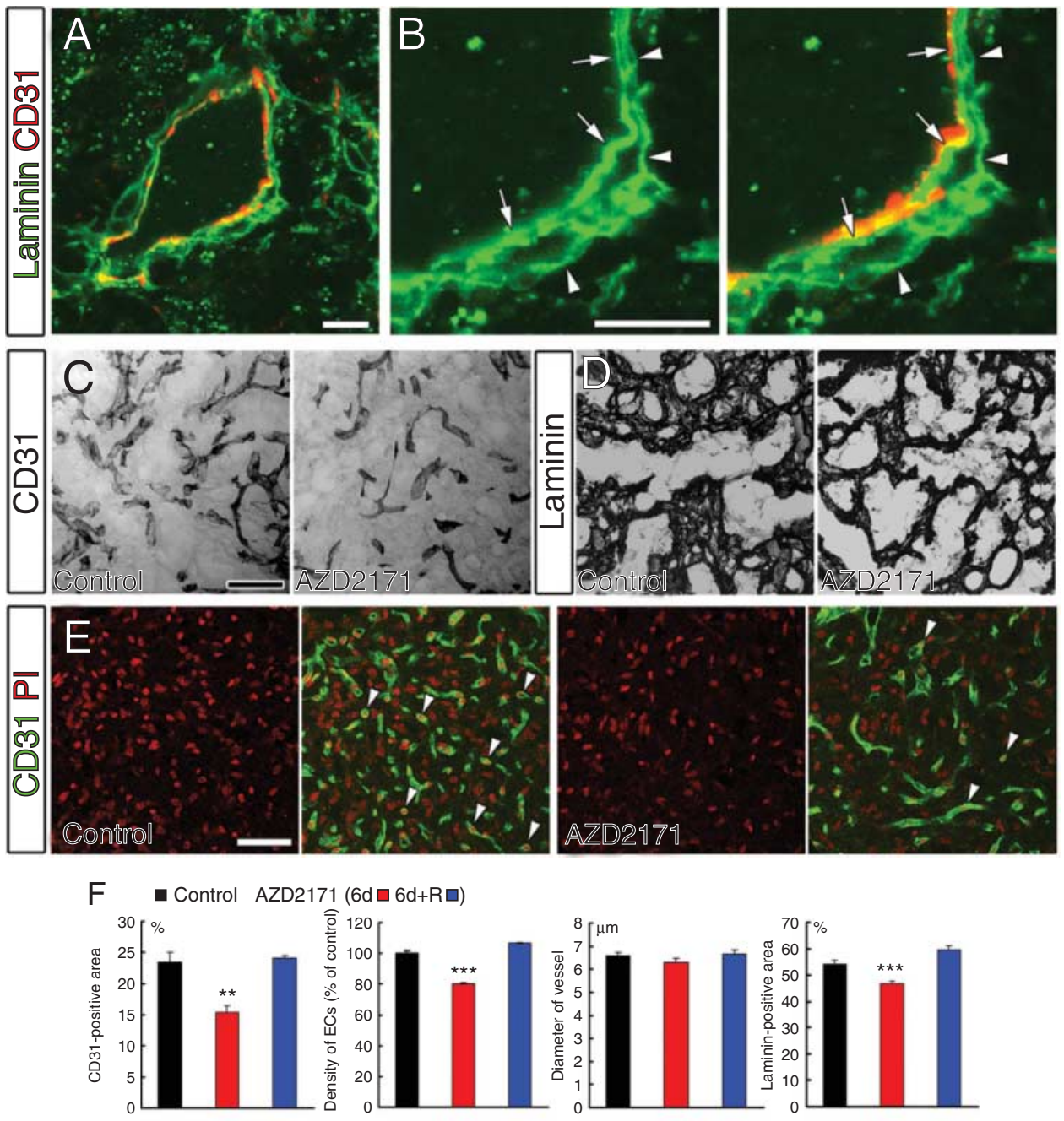

G

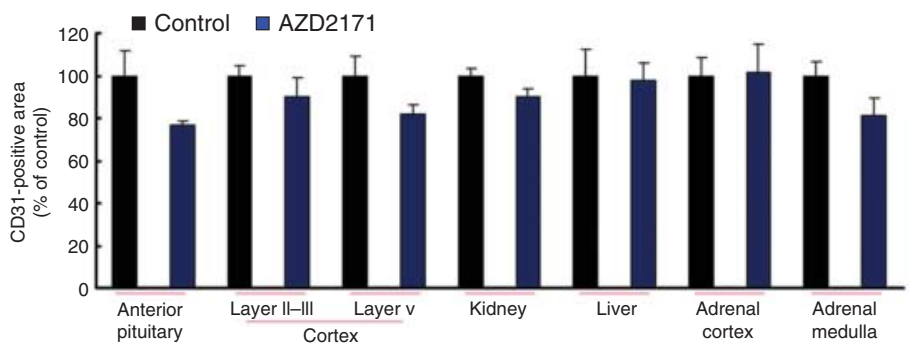

\section{Figure 6}

The effects of the VEGFR-associated tyrosine kinase inhibitor AZD2171 on vascular structure in the $\mathrm{NH}$ of adult mice. Animals received oral administration of AZD2171 ( $6 \mathrm{mg} / \mathrm{kg}$ per day) for 6 days and were fixed for the immunohistochemistry of CD31 and laminin. (A and B) Confocal images showing the presence of a large perivascular space around CD31-positive endothelial cells ( $A$ ) and two layers of the laminin-positive basement membrane (arrows and arrowheads in (B)). (C, D and E) Light microscopes, using a conventional chromogen method, revealing the reduction in the area of CD31-positive endothelial cells (C) and vascular area surrounded by a laminin-positive outer basement membrane (D) by administration of AZD2171. Confocal images showing that the number of CD31-positive endothelial cells (arrowheads) was decreased by administration of
AZD2171 (E). Scale bars represent $50 \mu \mathrm{m}$. ( $F$ and G) Administration of AZD2171 significantly decreased the area of CD31-immunoreactive endothelial cells and laminin-positive vascular area, and the number of CD31-positive endothelial cells, but did not change the diameter of CD31immunoreactive endothelial microvessels (F). Administration of AZD2171 did not change the area of CD31-immunoreactive endothelial cells in the anterior pituitary, the somatosensory cortex layers II-III and V, and the peripheral organs (G). 6d, 6-day administration of AZD2171; 6d+R, 6-day recovery after the withdrawal of AZD2171 treatment; ECs, endothelial cells; $\mathrm{PI}$, propidium iodide. Data are expressed as mean \pm s.E.M., $n=5, \star * P<0.01$ and $* * * P<0.001$ vs the control by ANOVA using Turkey's post hoc tests (F) and unpaired Student's $t$-test $(G)$.

Published by Bioscientifica Ltd. 

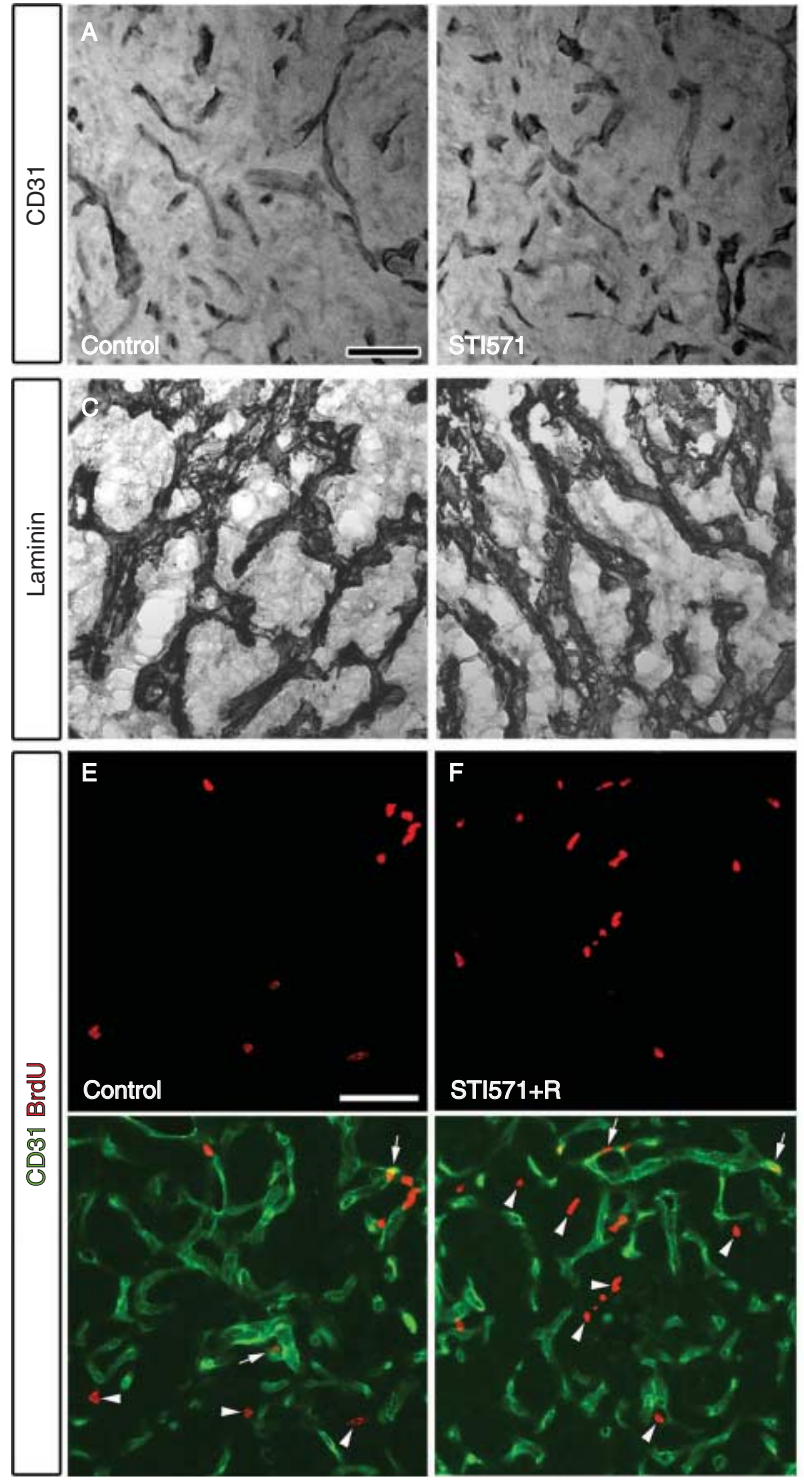

B

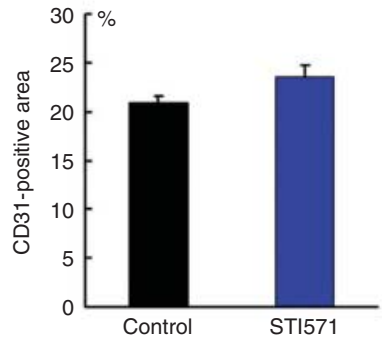

D

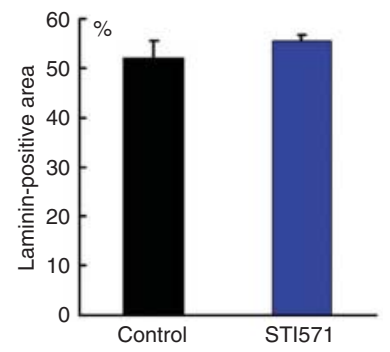

G
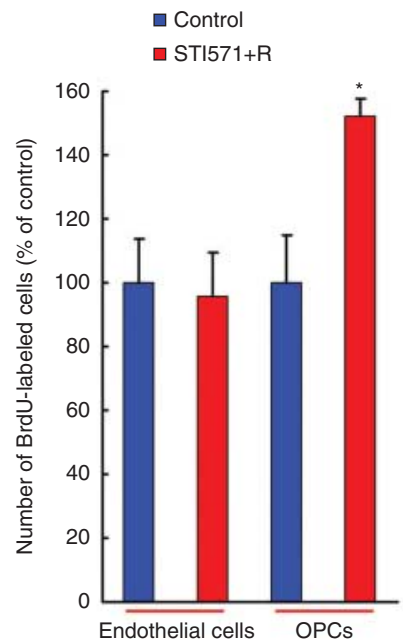

\section{Figure 7}

The effects of the PDGFR-associated tyrosine kinase inhibitor STI571 on vascular structure and proliferation of endothelial cells and OPCs after the withdrawal of STI571 treatment in the NH of adult mice. (A, B, C and D) Animals received oral administration of STI571 $(200 \mathrm{mg} / \mathrm{kg}$ per day) for 6 days and were fixed for the immunohistochemistry of CD31 and laminin. Light microscopes ( $A$ and $C$ ) and quantitative analysis ( $B$ and $D$ ) revealing no change in the area of CD31-positive endothelial cells and the lamininpositive vasculature by administration of STI571. (E, F and G) Animals received oral administration of the tyrosine kinase inhibitor STI571 (200 mg/kg per day) or vehicle for 6 days and then were kept without

AVP-immunoreactive axonal terminals $(P=0.0029$ by unpaired Student's $t$-test, $n=4$ ) and OXT-immunoreactive axonal terminals $(P=0.0020)$ when compared with the control (Fig. 9G). The density of AVP- and OXT-immunoreactive axonal terminals localized in close proximity to the vasculature was significantly decreased (AVP, $P=0.0060$ and
STI571 treatment for 6 days. After the withdrawal of STI571 treatment, animals were allowed to consume BrdU-containing water $(1 \mathrm{mg} / \mathrm{ml})$ for 6 days. The withdrawal of administration of STI57 slightly increased the number of BrdU-labeled OPCs (arrowheads) but not endothelial cells (arrows). ( $E$ and F) The quantitative analysis showed that the number of BrdU-labeled OPCs but not endothelial cells was significantly increased after the cessation of 6-day administration of STI571 when compared with the control (G). Scale bars represent $50 \mu \mathrm{m}$. Data are expressed as mean \pm s.E.M., $n=5,{ }^{*} P<0.05$ vs the control by unpaired Student's $t$-test.

OXT, $P=0.00077$ ) by treatment with AZD2171, while the density of AVP- and OXT-immunoreactive axonal terminals that were away from the vasculature was significantly increased (AVP, $P=0.0025$ and OXT, $P=0.00030$ ). Treatment with AZD2171 significantly increased the ratio of OXT-immunoreactive axonal terminal area, but not 


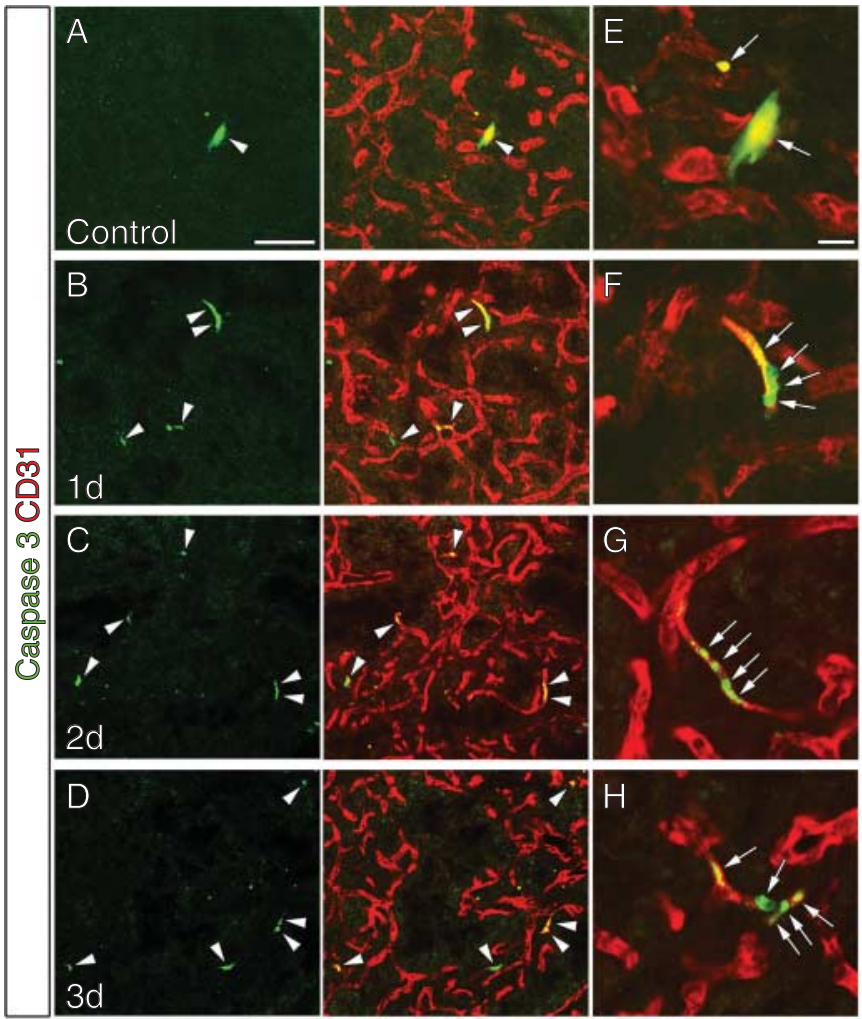

I

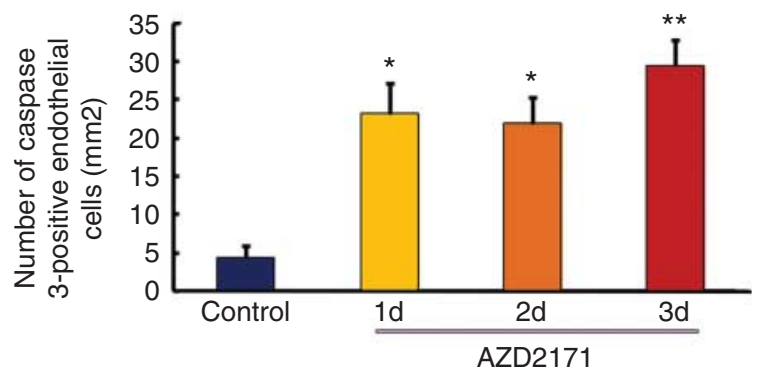

Figure 8

The effects of the VEGFR-associated tyrosine kinase inhibitor AZD2171 on apoptosis of endothelial cells in the $\mathrm{NH}$ of adult mice. Animals received oral administration of the tyrosine kinase inhibitor AZD2171 for VEGFRs $(6 \mathrm{mg} / \mathrm{kg}$ per day) twice daily for 1, 2, and 3 days. The rabbit IgG against caspase 3 detects endogenous levels of the activated caspase 3 resulting from a cleavage adjacent to Asp175 but does not recognize full-length caspase 3 or other cleaved caspases. (A, B, C, D, E, F, G and H) Confocal images showing that caspase 3-positive endothelial cells (arrowheads) were more frequently

AVP-immunoreactive axonal terminal area, to lamininpositive vascular area (AVP, $P>0.05$ and OXT, $P=0.0031$ ).

The quantitative analysis revealed that STI571 significantly decreased the density of total axonal terminals $(P=0.00029$ by unpaired Student's $t$-test, $n=4)$, axonal terminals localized in close proximity to the vasculature $(P=0.0013)$ and away from the vasculature $(P=0.00063)$ of AVP-immunoreactive neurons, and the area ratio of axonal terminals to the vasculature $(P=0.0019)$ when compared with the control (Fig. 9H). By contrast, all examined parameters of OXT-immunoreactive neurons were not changed by treatment with STI571 $(P>0.05)$.

\section{Discussion}

The present main finding is the demonstration of vascular dynamics in the $\mathrm{NH}$ of adult mice.

observed in AZD2171-treated mice when compared with the control (A, B, C and D). High-magnification views revealed that caspase3-positive endothelial cells (arrows) were continuously distributed ( $E, F, G$ and $H)$. Scale bars represent $50 \mu \mathrm{m}$. (I) The quantitative analysis showed that the number of caspase 3-positive endothelial cells was significantly higher at days 1, 2, and 3 of administration of AZD2171 when compared with the control. Data are expressed as mean \pm s.E.M., $n=4, * P<0.05$ and $* * P<0.01$ vs the control by ANOVA using Turkey's post hoc tests.

The inhibition of VEGF signaling decreased proliferation of endothelial cells and OPCs but promoted apoptosis of endothelial cells, which resulted in a low vascular density. Moreover, the withdrawal of VEGFR signaling inhibition caused prominent rebound proliferation of endothelial cells but not OPCs. The inhibition of PDGF signaling did not change the vascular structure and cause rebound proliferation of endothelial cells, although it decreased proliferation of endothelial cells and OPCs. The inhibition of VEGF signaling decreased the density of both AVP- and OXT-containing axonal terminals and that of PDGF signaling decreased the density of only AVP-containing axonal terminals. These results offer the key to an understanding of the fundamental property of fenestrated vasculature in neurosecretory brain regions and, moreover, shed light on a new aspect to understand neurosecretion.

Published by Bioscientifica Ltd. 


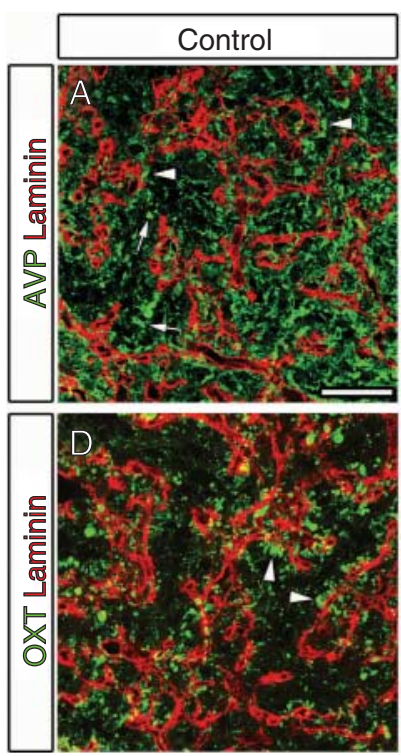

G
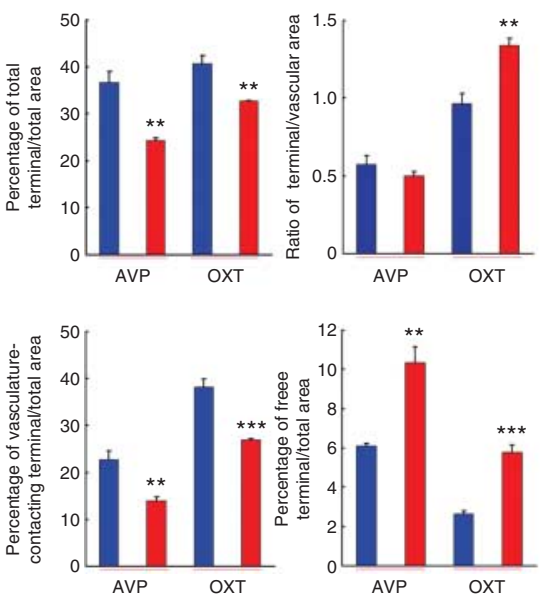

Figure 9

The effects of VEGFR- and PDGFR-associated tyrosine kinase inhibitors on the density of AVP- and OXT-containing axonal terminals in the $\mathrm{NH}$ of adult mice. Animals received oral administration of AZD2171 (6 mg/kg per day) or STI571 (200 mg/kg per day) for 6 days and were fixed for the immunohistochemistry. (A, B, C, D, E and F) Confocal images showed that the density of AVP-immunoreactive axonal terminals was reduced by administration of AZD2171 and STI571 (A, B and C). The density of OXT-immunoreactive axonal terminals was reduced by administration of AZD2171 but not STI571 (D, E and F). Arrowheads and arrows indicate axonal terminals in contact and without contact with the vasculature respectively. Scale bar represents $50 \mu \mathrm{m}$. ( $\mathrm{G}$ and $\mathrm{H})$ The quantitative analysis showed that treatment with AZD2171 decreased the area of total

\section{Continuous angiogenesis}

In this study, we found many BrdU-labeled and Ki-67positive nuclei in the endothelial cells of adult mice. Moreover, the expression of principal angiogenesisinducing mediators, VEGFA and VEGFR2, was found in pituicytes and endothelial cells, respectively, in the
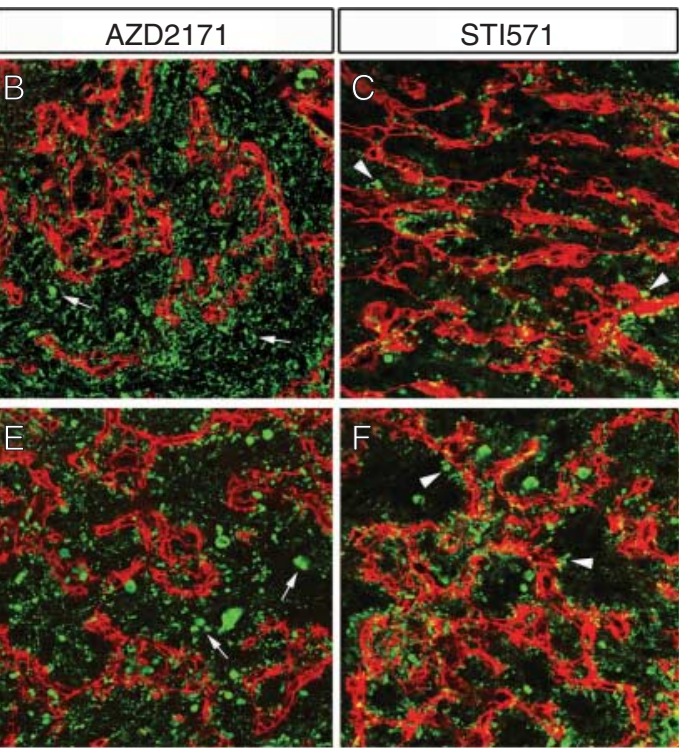

$\mathrm{H} \quad \square$ Control $\quad \square \mathrm{sTI571}$
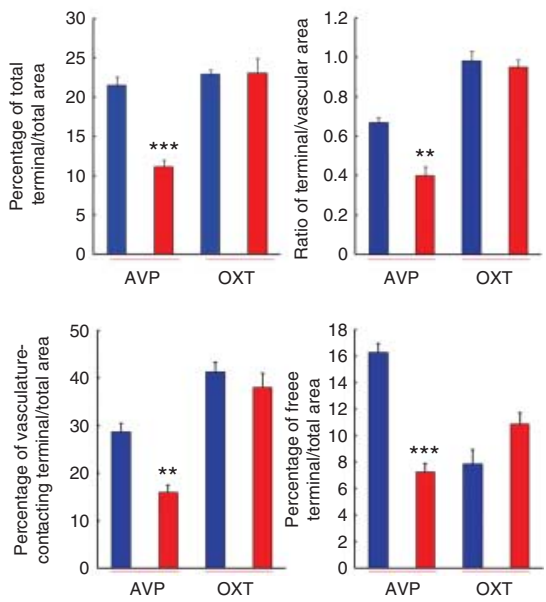

AVP-immunoreactive axonal terminals and AVP-immunoreactive axonal terminals in contact with the vasculature but increased the area of AVP-immunoreactive axonal terminals not in contact with the vasculature (G). Same changes were observed in OXT-immunoreactive axonal terminals of AZD2171-treated animals, except that the area ratio of axonal terminal to the vasculature was increased. Treatment with STI571 decreased the area of total axonal terminals, axonal terminals in contact and without contact with the vasculature, and the ratio of axonal terminals to the vasculature in AVP-immunoreactive neurons but not the OXT-immunoreactive ones (H). Data are expressed as mean \pm S.E.M., $n=4, * * P<0.01$ and $* * * P<0.001$ vs the control by unpaired Student's $t$-test.

$\mathrm{NH}$ of adult mice. A previous in situ hybridization study has reported higher expression of Vegfa mRNA in the $\mathrm{NH}$ when compared with the anterior and intermediate pituitary (Ochoa et al. 2000). It has been shown that astrocyte-derived VEGFA plays a crucial role in the formation and growth of new blood vessels in the 
developing brain (Bozoyan et al. 2012) and retina (Gerhardt et al. 2003, Scott et al. 2010). Proliferation of endothelial cells is mainly regulated by the signaling of VEGFA and VEGFR2 in the developing vasculature (Gerhardt et al. 2003, Somanath et al. 2009). The expression level of total Vegfa mRNA is high during early embryonic period but it gradually decreases along with brain maturation (Ng et al. 2001, Mackenzie \& Ruhrberg 2012). It is also known that the expression pattern of the VEGFA isoform is different depending on developmental stages and tissues. Although the expression level of $V e g f a_{120}$ mRNA is remarkably high at the early embryonic period and gradually decreases thereafter, the level of $V e g f a_{164}$ mRNA increases along with the brain development and the level of $V e g f a_{188}$ is relatively low and constant throughout life ( $\mathrm{Ng}$ et al. 2001). Transgenic mice that express only $V e g f a_{120}$ result in lethality just before or after the birth (Karkkainen et al. 2004), while animals overexpressing $V e g f a_{120}$ in the forebrain augment angiogenesis in the hippocampus (Udo et al. 2008). The present pharmacological experiment using the selective VEGFR inhibitor AZD2171 largely attenuated proliferation of endothelial cells in the NH. Moreover, the withdrawal of administration of the VEGFR signaling inhibitor induced drastic rebound proliferation of endothelial cells. On the other hand, the expression of VEGFR3 was observed at AVP- and OXT-containing axonal terminals and pituicytes. VEGFR3 is reported to bind with VEGFC and VEGFD but not with VEGFA (Karkkainen et al. 2004, Roberts et al. 2006). VEGFR1 has a binding affinity for VEGFA and VEGFB and an inhibitory effect on proliferation of endothelial cells (Keyt et al. 1996, Fong et al. 1999). Our previous study has demonstrated continuous proliferation of endothelial cells and the expression of angiogenesis-associated proteins such as NG2 (CSPG4), PDGFRB, and Delta-like ligand 4 in the ME of adult mice (Morita et al. 2013). It is concluded that VEGFA and VEGFR2 together play a crucial role in continuous angiogenesis in the $\mathrm{NH}$ of adult mice, which is a common feature in two neurosecretory brain regions.

\section{Significance of VEGF signaling}

This study revealed that administration of the VEGFR signaling inhibitor AZD2171 for 6 days largely reduced the area of CD31-positive endothelial cells and the lamininpositive vasculature in the $\mathrm{NH}$, but not in the anterior pituitary, the cerebral cortex, and the peripheral organs. It is reported that administration of VEGF signaling inhibitors for 14 and 21 days reduces the area of endothelial cells in the islets of the pancreas, the thyroid, the adrenal cortex, the anterior pituitary, and the $\mathrm{NH}$, but not in the acini of pancreas, the adrenal medulla, and the cerebral cortex of brains (Kamba et al. 2006). This difference is probably due to the time period of VEGF inhibitor treatment, indicating that the control of neurohypophysial vascular density is much more dependent on the VEGF signaling when compared with other tissues. In this study, moreover, we found that the decrease in the number of endothelial cells resulted from the promotion of endothelial cell apoptosis rather than simply the attenuation of their proliferation. Moreover, the withdrawal of AZD2171 treatment increased the number of BrdU-labeled endothelial cells and rapidly returned to the control level, while such dramatic rebound proliferation was not observed after the withdrawal of the PDGFR inhibitor STI571. There is no doubt that the surface of the vascular basement membrane is important for neurosecretion to interact with axonal terminals of AVP- and OXT-containing neurons (Tweedle \& Hatton 1987, Miyata et al. 2001, Miyata $\&$ Hatton 2002). Thus, these experiments demonstrate that VEGF signaling is a crucial mediator for proliferation and apoptosis of endothelial cells, indicating the presence of VEGF-dependent regulatory mechanism to control the vascular density in the $\mathrm{NH}$ of adult mice.

In this study, the inhibition of VEGF signaling largely decreased the density of AVP- and OXT-containing axonal terminals. The density of axonal terminals in contact with the vasculature was reduced, while that of axonal terminals not in contact with the vasculature was increased. In the adult songbird brain, new neurons arise from the ventricular zone and are recruited to the higher vocal center. VEGF-dependent endothelial cell division and angiogenesis provide microvascular expansion in the higher vocal center, which in turn secretes the brainderived neurotropic factor to support the recruitment of newly generated neurons (Louissaint et al. 2002, Chen et al. 2013a,b). The perivascular niche provides a source of both trophic support and migratory cues for the newly generated neural stem/progenitor cells. The tenascin, laminin, heparan sulfates, and chondroitin sulfate proteoglycans have all been identified as perivascular substrates for neuronal migration in the subventricular zone and rostral migratory stream (Goldman \& Chen 2011). The expression of tenascin C (Theodosis et al. 1997), laminin (Imamura et al. 2010), and chondroitin sulfate proteoglycans (Morita et al. 2010) has been reported in the $\mathrm{NH}$. These results imply the presence of perivascular niche for VEGF-dependent coordinate regulation of axonal terminals and endothelial cells in the $\mathrm{NH}$ of adult mice.

Published by Bioscientifica Ltd 
VEGF has been shown to increase microvascular permeability and endothelial fenestration (Roberts \& Palade 1995). The activation of VEGFR2 also alters extracellular matrix, as well as adherens junctions and tight junctions (Zhang \& Chopp 2002, Sandoval \& Witt 2008). A role of the Src pathway in the downregulation of adherens and tight junction proteins has already been demonstrated (Gavard \& Gutkind 2006, Takenaga et al. 2009). In fetal brains, vascular permeability of high-molecular-mass molecules is very low as in the adult brains (Armulik et al. 2010, Daneman et al. 2010), whereas the permeability of low-molecular-mass molecules $(<1000)$ is higher in fetal brains than in adult brains (Tuor et al. 1992, Keep et al. 1995). Thus, VEGFA may be a possible mediator to determine the fenestrated feature of the neurohypophysial vasculature.

\section{Significance of PDGF signaling}

PDGFB and PDGFRB are highly expressed in endothelial cells and pericytes, respectively, in the developing vasculature (Lindahl et al. 1997). PDGFRB has a binding affinity for PDGFB but not PDGFA, whereas PDGFRA is able to bind to both PDGFA and PDGFB (Chen et al. $2013 a, b)$. The present immunohistochemistry revealed that PDGFB and PDGFRB were highly expressed in OXTcontaining axonal terminals and pericytes respectively. It has been demonstrated that PDGFRA is expressed specifically in OPCs in the NH of adult rats (Virard et al. 2008). The present pharmacological experiment using the selective PDGFR inhibitor STI571 largely diminished proliferation of endothelial cells in the $\mathrm{NH}$ of adult mice. The signaling of PDGFB and PDGFRB plays a crucial role in the interaction of pericytes with endothelial cells by controlling the migration and shape conversion of pericytes (Lindahl et al. 1997, Fukushi et al. 2004, Ribatti et al. 2011, Winkler et al. 2011). The PDGFR inhibitor STI571 has been shown to inhibit angiogenesis by preventing PDGFRB of pericytes (Bauman et al. 2007, Rocha et al. 2007). In this study, PDGFB is stored within OXT-containing neurosecretory granules, suggesting that PDGFB is co-released with OXT from axonal terminals. It has been suggested that localized secretion of OXT is important for the integrity of neurovascular contacts in the $\mathrm{NH}$ of developing zebrafish (Gutnick et al. 2011). Axonal fibers of the peripheral sensory neurons regulate the pattern of arterial branching via local secretion of VEGFA $_{160 / 120}$ (Mukouyama et al. 2002, 2005). Therefore, it is possible that PDGF signaling controls proliferation of endothelial cells possibly through an indirect interaction between pericytes and endothelial cells.
This study demonstrated that the inhibition of PDGF signaling reduced the density of AVP-containing axonal terminals without changing the vascular density. Recently, we have found that Notch3 and a Notch ligand Delta-like ligand 4 are specifically expressed in OXTcontaining axonal terminals and pituicytes respectively (Mannari \& Miyata 2014). This observation indicates the specific interaction between OXT-containing axonal terminals and pituicytes and/or OPCs to discriminate OXT-containing axonal terminals from the AVPcontaining ones. This study demonstrated that PDGFB was highly expressed in OXT-containing axonal terminals but not in the AVP-containing ones. Thus, it is possible that PDGFB derived from OXT-containing axonal terminals may be necessary for the maintenance of AVP-containing axonal terminals.

In this study, the inhibition of PDGFR signaling prominently inhibited proliferation of OPCs in the NH. It has been demonstrated that PDGFRA-expressing OPCs are shown to proliferate and differentiate into pituicytes and the chronic salt loading significantly increased proliferation of OPCs in the NH of adult rats (Virard et al. 2008). It has been reported that proliferation of OPCs is mediated through PDGF and neurotropin 3 (Robinson \& Miller 1996). Fibroblast growth factor 2 and PDGF promote the survival, migration, and differentiation of OPCs in the subventricular zone (Lachapelle et al. 2002). While physiological concentrations of PDGF were not in themselves sufficient to promote OPC proliferation, PDGF-mediated integrin activation is the critical integrative step in proliferation signaling of OPCs (Baron et al. 2002). These results suggest that proliferation of OPCs may be controlled partly through the signaling of PDGF in the $\mathrm{NH}$.

\section{Declaration of interest}

The authors declare that there is no conflict of interest that could be perceived as prejudicing the impartiality of the research reported.

\section{Funding}

This work was supported in part by Scientific Research Grants from the Japan Society for the Promotion of Science (no. 24500411 to S M).

\section{Acknowledgements}

The hybridoma of anti-CD31 (2H8, Dr Steven Bogen) was obtained from the DSHB developed under the auspices of the NICHD and maintained by the University of lowa, lowa City, IA 52242, USA. The authors are grateful to Dr H Gainer for generous supplies of monoclonal antibodies against OXTand AVP-neurophysin.

Published by Bioscientifica Ltd. 


\section{References}

Abbott NJ, Patabendige AA, Dolman DE, Yusof SR \& Begley DJ 2010 Structure and function of the blood-brain barrier. Neurobiology of Disease 37 13-25. (doi:10.1016/j.nbd.2009.07.030)

Armulik A, Genové G, Máe M, Nisanciouglu MH, Wallgard E, Niaudet C, He L, Norlin J, Lindblom P, Strittmatter K et al. 2010 Pericytes regulate the blood-brain barrier. Nature 468 557-561. (doi:10.1038/nature09522)

Baron W, Shattil SJ \& ffrench-Constant C 2002 The oligodendrocyte precursor mitogen PDGF stimulates proliferation by activation of $\alpha(\mathrm{v}) \beta 3$ integrins. EMBO Journal 21 1957-1966. (doi:10.1093/emboj/21.8.1957)

Bauman JE, Eaton KD \& Martins RG 2007 Antagonism of platelet-derived growth factor receptor in non small cell lung cancer: rationale and investigations. Clinical Cancer Research 13 s4632-s4636. (doi:10.1158/ 1078-0432.CCR-07-0212)

Ben-Barak Y, Russell JT, Whitnall MH, Ozato K \& Gainer H 1985 Neurophysin in the hypothalamo-neurohypophysial system. I. Production and characterization of monoclonal antibodies. Journal of Neuroscience 5 81-97.

Bozoyan L, Khlghatyan J \& Saghatelyan A 2012 Astrocytes control the development of the migration-promoting vasculature scaffold in the postnatal brain via VEGF signaling. Journal of Neuroscience $\mathbf{3 2}$ 1687-1704. (doi:10.1523/JNEUROSCI.5531-11.2012)

Brown WR \& Thore CR 2011 Review: Cerebral microvascular pathology in ageing and neurodegeneration. Neuropathology and Applied Neurobiology 37 56-74. (doi:10.1111/j.1365-2990.2010.01139.x)

Carmeliet P, Ferreira V, Breier G, Pollefeyt S, Kieckens L, Gertsenstein M, Fahrig M, Vandenhoeck A, Harpal K, Eberhardt C et al. 1996 Abnormal blood vessel development and lethality in embryos lacking a single VEGF allele. Nature 380 435-439. (doi:10.1038/380435a0)

Chen P-H, Chen X \& He X 2013a Platelet-derived growth factors and their receptors: structural and functional perspectives. Biochimica et Biophysica Acta 1834 2176-2186. (doi:10.1016/j.bbapap.2012.10.015)

Chen Z, Ye R \& Goldman SA 2013b Testosterone modulation of angiogenesis and neurogenesis in the adult songbird brain. Neuroscience 239 139-148. (doi:10.1016/j.neuroscience.2012.12.043)

Ciofi P, Garret M, Lapirot O, Lafon P, Loyens A, Prévot V \& Levine JE 2009 Brain-endocrine interactions: a microvascular route in the mediobasal hypothalamus. Endocrinology 150 5509-5519. (doi:10.1210/en.2009-0584)

Ciofi P 2011 The arcuate nucleus as a circumventricular organ in the mouse. Neuroscience Letters 487 187-190. (doi:10.1016/j.neulet.2010.10.019)

Daneman R, Zho Lu, Kebede AA \& Barres BA 2010 Pericytes are required for blood-brain barrier integrity during embryogenesis. Nature $\mathbf{4 6 8}$ 562-566. (doi:10.1038/nature09513)

Engelhardt B 2003 Development of the blood-brain barrier. Cell and Tissue Research 314 119-129. (doi:10.1007/s00441-003-0751-z)

Fong GH, Zhang L, Bryce DM \& Peng J 1999 Increased hemangioblast commitment, not vascular disorganization, is the primary defect in flt-1 knock-out mice. Development 126 3025-3035.

Fukushi J, Makagiansar IT \& Stallcup WB 2004 NG2 proteoglycan promotes endothelial cell motility and angiogenesis via engagement of galectin-3 and 31 integrin. Molecular Biology of the Cell 15 3580-3590. (doi:10.1091/mbc.E04-03-0236)

Gavard J \& Gutkind JS 2006 VEGF controls endothelial-cell permeability by promoting the $\beta$-arrestin-dependent endocytosis of VE-cadherin. Nature Cell Biology 8 1223-1234. (doi:10.1038/ncb1486)

Gerhardt H, Golding M, Fruttinger M, Ruhrberg C, Lundkvist A, Abramsson A, Jeltsch M, Mitchell C, Alitalo K, Shima D et al. 2003 VEGF-A guides angiogenic sprouting utilizing endothelial tip cell filopodia. Journal of Cell Biology 161 1163-1177. (doi:10.1083/jcb.200302047)

Goldman SA \& Chen Z 2011 Perivascular instruction of cell genesis and fate in the adult brain. Nature Neuroscience 14 1382-1389. (doi:10.1038/nn.2963)

Gutnick A, Blechman J, Kaslin J, Herwig L, Belting HG, Affolter M, Bonkowsky JL \& Levkowitz G 2011 The hypothalamic neuropeptide oxytocin is required for formation of the neurovascular interface of the pituitary. Developmental Cell 21 642-654. (doi:10.1016/j.devcel.2011. 09.004)

Imamura Y, Morita S, Nakatani N, Okada K, Ueshima S, Matsuo O \& Miyata S 2010 Tissue plasminogen activator and plasminogen are critical for osmotic homeostasis by regulating vasopressin secretion. Journal of Neuroscience Research 88 1995-2006. (doi:10.1002/jnr.22370)

Kamba T, Tam BY, Hashizume H, Haskell A, Sennino B, Mancuso MR, Norberg SM, O'Brien SM, Davis RB, Gowen LC et al. 2006 VEGFdependent plasticity of fenestrated capillaries in the normal adult microvasculature. American Journal of Physiology 290 H560-H576.

Karkkainen MJ, Haiko P, Sainio K, Partanen J, Taipale J, Petrova TV, Jeltsch M, Jackson DG, Talikka M, Rauvala H et al. 2004 Vascular endothelial growth factor $\mathrm{C}$ is required for sprouting of the first lymphatic vessels from embryonic veins. Nature Immunology 5 74-80. (doi:10.1038/ni1013)

Keep RF, Ennis SR, Beer ME \& Betz AL 1995 Developmental changes in blood-brain barrier potassium permeability in the rat: relation to brain growth. Journal of Physiology $\mathbf{4 8 8} 439-448$.

Keyt BA, Nguyen HV, Berleau LT, Duarte CM, Park J, Chen H \& Ferrara N 1996 Identification of vascular endothelial growth factor determinants for binding KDR and FLT-1 receptors. Generation of receptor-selective VEGF variants by site-directed mutagenesis. Journal of Biological Chemistry 271 5638-5646. (doi:10.1074/jbc.271.10.5638)

Kozlowski GP \& Coates PW 1985 Ependymoneuronal specializations between LHRH fibers and cells of the cerebroventricular system. Cell and Tissue Research 242 301-311. (doi:10.1007/BF00214542)

Lachapelle F, Avellana-Adalid V, Nait-Oumesmar B \& Baron-Van Evercooren A 2002 Fibroblast growth factor-2 (FGF-2) and platelet-derived growth factor $\mathrm{AB}$ (PDGF AB) promote adult SVZ-derived oligodendrogenesis in vivo. Molecular and Cellular Neurosciences 20 390-403. (doi:10.1006/mcne.2002.1124)

Lindahl P, Johansson BR, Levéen P \& Betsholtz C 1997 Pericyte loss and microaneurysm formation in PDGF-B-deficient mice. Science $\mathbf{2 7 7}$ 242-245. (doi:10.1126/science.277.5323.242)

Louissaint A Jr, Rao S, Leventhal C \& Goldman SA 2002 Coordinated interaction of neurogenesis and angiogenesis in the adult songbird brain. Neuron 34 945-960. (doi:10.1016/S0896-6273(02)00722-5)

Mackenzie F \& Ruhrberg C 2012 Diverse roles for VEGF-A in the nervous system. Development 139 1371-1380. (doi:10.1242/dev.072348)

Mannari T \& Miyata S 2014 Activity-dependent Notch signaling in the hypothalamo-neurohypophysial system of adult mouse brains. Journal of Neuroendocrinology [in press].

Mannari T, Morita S, Furube E, Tominaga M \& Miyata S 2014 Astrocytic TRPV1 ion channels detect blood-borne signals in the sensory circumventricular organs of adult mouse brains. Glia 61 957-971. (doi:10.1002/glia.22488)

Miyata S \& Hatton GI 2002 Activity-related, dynamic neuron-glial interactions in the hypothalamo-neurohypophysial system. Microscopy Research and Technique 56 143-157. (doi:10.1002/jemt.10012)

Miyata S \& Morita S 2011 A new method for visualization of endothelial cells and extravascular leakage in adult mouse brain using fluorescein isothiocyanate. Journal of Neuroscience Methods 202 9-16. (doi:10.1016/ j.jneumeth.2011.08.002)

Miyata S, Takamatsu H, Maekawa S, Matsumoto N, Watanabe K, Kiyohara T \& Hatton GI 2001 Plasticity of neurohypophysial terminals with increased hormonal release during dehydration: ultrastructural and biochemical analyses. Journal of Comparative Neurology 434 413-427. (doi:10.1002/cne.1184)

Morita S \& Miyata S 2012 Different vascular permeability between the sensory and secretory circumventricular organs of adult mouse brain. Cell and Tissue Research 349 589-603. (doi:10.1007/s00441-012-1421-9)

Morita S \& Miyata S 2013 Accessibility of low-molecular-mass molecules to the median eminence and arcuate hypothalamic nucleus of adult mouse. Cell Biochemistry and Function 31 668-677. (doi:10.1002/cbf.2953)

Morita S, Oohira A \& Miyata S 2010 Activity-dependent remodeling of chondroitin sulfate proteoglycans extracellular matrix in the 
hypothalamo-neurohypophysial system. Neuroscience 166 1068-1082. (doi:10.1016/j.neuroscience.2010.01.041)

Morita S, Ukai S \& Miyata S 2013 VEGF-dependent continuous angiogenesis in the median eminence of adult mice. European Journal of Neuroscience 37 508-518. (doi:10.1111/ejn.12047)

Mukouyama YS, Shin D, Britsch S, Taniguchi M \& Anderson DJ 2002 Sensory nerves determine the pattern of arterial differentiation and blood vessel branching in the skin. Cell 109 693-705. (doi:10.1016/ S0092-8674(02)00757-2)

Mukouyama YS, Gerber HP, Ferrara N, Gu C \& Anderson DJ 2005 Peripheral nerve-derived VEGF promotes arterial differentiation via neuropilin 1-mediated positive feedback. Development 132 941-952. (doi:10.1242/ dev.01675)

Müller EE, Locatelli V \& Cocchi D 1999 Neuroendocrine control of growth hormone secretion. Physiological Reviews 79 511-607.

Mullier A, Bouret SG, Prevot V \& Dehouck B 2010 Differential distribution of tight junction proteins suggests a role for tanycytes in bloodhypothalamus barrier regulation in the adult mouse brain. Journal of Comparative Neurology 518 943-962. (doi:10.1002/cne.22273)

Namimatsu S, Ghazizadeh M \& Sugisaki Y 2005 Reversing the effects of formalin fixation with citraconic anhydride and heat: a universal antigen retrieval method. Journal of Histochemistry and Cytochemistry $\mathbf{5 3}$ 3-11. (doi:10.1369/jhc.4C6466.2005)

Ng YS, Rohan R, Sunday ME, Demello DE \& D'Amore PA 2001 Differential expression of VEGF isoforms in mouse during development and in the adult. Developmental Dynamics 220 112-121. (doi:10.1002/10970177(2000)9999:9999\%3C;::AID-DVDY1093\%3E;3.0.CO;2-D)

Norsted E, Gömüç B \& Meister B 2008 Protein components of the bloodbrain barrier (BBB) in the mediobasal hypothalamus. Journal of Chemical Neuroanatomy 36 107-121. (doi:10.1016/j.jchemneu.2008.06.002)

Ochoa AL, Mitchner NA, Paynter CD, Morris RE \& Ben-Jonathan N 2000 Vascular endothelial growth factor in the rat pituitary: differential distribution and regulation by estrogen. Journal of Endocrinology 165 483-492. (doi:10.1677/joe.0.1650483)

Ogunshola OO, Stewart WB, Mihalcik V, Solli R, Madri JA \& Ment LR 2000 Neuronal VEGF-A expression correlates with angiogenesis in postnatal developing rat brain. Developmental Brain Research 119 139-153. (doi:10.1016/S0165-3806(99)00125-X)

Ojeda SR, Urbanski HF, Costa ME, Hill DF \& Moholt-Siebertm M 1990 Involvement of transforming growth factor $\alpha$ in the release of luteinizing hormone-releasing hormone from the developing female hypothalamus. PNAS 87 9698-9702. (doi:10.1073/pnas.87.24.9698)

Ojeda SR, Lomniczi A \& Sandau US 2008 Glial-gonadotrophin hormone $(\mathrm{GnRH})$ neurone interactions in the median eminence and the control of GnRH secretion. Journal of Neuroendocrinology 20 732-742. (doi:10.1111/j.1365-2826.2008.01712.x)

Prevot V 2002 Glial-neuronal-endothelial interactions are involved in the control of GnRH secretion. Journal of Neuroendocrinology 14 247-255. (doi:10.1046/j.0007-1331.2001.00772.x)

Prevot V, Bellefontaine N, Baroncini M, Sharif A, Hanchate NK, Parkash J, Campagne C \& de Seranno S 2010 Gonadotrophin-releasing hormone nerve terminals, tanycytes and neurohaemal junction remodelling in the adult median eminence: functional consequences for reproduction and dynamic role of vascular endothelial cells. Journal of Neuroendocrinology 22 639-649. (doi:10.1111/j.1365-2826.2010.02033.x)

Ribatti D, Niko B \& Crivellato E 2011 The role of pericytes in angiogenesis. International Journal of Developmental Biology 55 261-268. (doi:10.1387/ ijdb.103167dr)

Roberts WG \& Palade GE 1995 Increased microvascular permeability and endothelial fenestration induced by vascular endothelial growth factor. Journal of Cell Science 108 2369-2379.
Roberts N, Kloos B, Cassella M, Podgrabinska S, Persaud K, Wu Y, Pytowski B \& Skobe M 2006 Inhibition of VEGFR-3 activation with the antagonistic antibody more potently suppresses lymph node and distant metastases than inactivation of VEGFR-2. Cancer Research $6 \mathbf{6}$ 2650-2657. (doi:10.1158/0008-5472.CAN-05-1843)

Robinson S \& Miller R 1996 Environmental enhancement of growth factormediated oligodendrocyte precursor proliferation. Molecular and Cellular Neurosciences 8 38-52. (doi:10.1006/mcne.1996.0042)

Rocha A, Azevedo I \& Soares R 2007 Anti-angiogenic effects of imatinib target smooth muscle cells but not endothelial cells. Angiogenesis 10 279-286. (doi:10.1007/s10456-007-9080-2)

Sandoval KE \& Witt KA 2008 Blood-brain barrier tight junction permeability and ischemic stroke. Neurobiology of Disease 32 200-219. (doi:10.1016/j.nbd.2008.08.005)

Scott A, Powner MB, Gandhi P, Clarkin C, Gutmann DH, Johnson RS, Ferrara N \& Fruttiger M 2010 Astrocyte-derived vascular endothelial growth factor stabilizes vessels in the developing retinal vasculature. PLOS ONE 5 e11863. (doi:10.1371/journal.pone.0011863)

Shalaby F, Rossant J, Yamaguchi TP, Gersenstein M, Wu XF, Breitman ML \& Schuh AC 1995 Failure of blood-island formation and vasculogenesis in Flk-1-deficient mice. Nature 376 62-66. (doi:10.1038/376062a0)

Smithson KG, Suarez I \& Hatton GI 1990 ß-Adrenergic stimulation decreases glial and increases neural contact with the basal lamina in rat neurointermediate lobes incubated in vitro. Journal of Neuroendocrinology 2 693-699. (doi:10.1111/j.1365-2826.1990.tb00466.x)

Somanath PR, Malinin NL \& Byzova TV 2009 Cooperation between integrin $\alpha \mathrm{v} \beta 3$ and VEGFR2 in angiogenesis. Angiogenesis 12 177-185. (doi:10.1007/s10456-009-9141-9)

Takenaga Y, Takagi N, Murotomi K, Tanonaka K \& Takeo S 2009 Inhibition of $\mathrm{Src}$ activity decreases tyrosine phosphorylation of occludin in brain capillaries and attenuates increase in permeability of the blood-brain barrier after transient focal cerebral ischemia. Journal of Cerebral Blood Flow and Metabolism 29 1099-1108. (doi:10.1038/jcbfm.2009.30)

Theodosis DT, Pierre K, Cadoret MA, Allard M, Faissner A \& Poulain DA 1997 Expression of high levels of the extracellular matrix glycoprotein, tenascin-C, in the normal adult hypothalamoneurohypophysial system. Journal of Comparative Neurology 379 386-398. (doi:10.1002/(SICI)1096-9861(19970317)379:3\%3C;386:: AID-CNE5\%3E;3.0.CO;2-)

Tuor UI, Simon C \& Bascaramurtyy S 1992 Local blood-brain aminoisobutyric acid transfer within medulla, cortex, and selected brain area. Journal of Neurochemistry 59 999-1007. (doi:10.1111/j.1471-4159.1992. tb08341.x)

Tweedle CD \& Hatton GI 1987 Morphological adaptability at neurosecretory axonal endings on the neurovascular contact zone of the rat neurohypophysis. Neuroscience 20 241-246. (doi:10.1016/03064522(87)90016-9)

Udo H, Yoshida Y, Kino T, Ohnuki K, Mizunoya W, Mukuda T \& Sugiyama H 2008 Enhanced adult neurogenesis and angiogenesis and altered affective behaviors in mice overexpressing vascular endothelial growth factor 120. Journal of Neuroscience 31 14522-14536. (doi:10.1523/JNEUROSCI.3673-08.2008)

Virard I, Gubkina O, Alfonsi F \& Durbec P 2008 Characterization of heterogeneous glial cell populations involved in dehydration-induced proliferation in the adult rat neurohypophysis. Neuroscience 151 82-91. (doi:10.1016/j.neuroscience.2007.10.035)

Winkler EA, Bell RD \& Zlokovic BV 2011 Central nervous system pericytes in health and disease. Nature Neuroscience 14 1398-1405. (doi:10.1038/ nn.2946)

Zhang Z \& Chopp M 2002 Vascular endothelial growth factor and angiopoietins in focal cerebral ischemia. Trends in Cardiovascular Medicine 12 62-66. (doi:10.1016/S1050-1738(01)00149-9)

Received in final form 29 April 2014

Accepted 21 May 2014

Accepted Preprint published online 22 May 2014 http://joe.endocrinology-journals.org DOI: 10.1530/JOE-14-0075
C 2014 Society for Endocrinology Printed in Great Britain 